\title{
Avaliação da condutividade hidraulica do solo saturada utilizando dois métodos de laboratório numa topossequência com diferentes coberturas vegetais no Baixo Amazonas '
}

\author{
Jean Dalmo de Oliveira MARQUES ${ }^{2}$, Wenceslau Geraldes TEIXEIRA ${ }^{3}$, Ana Maria REIS ${ }^{4}$, \\ Orlando Ferreira CRUZ JUNIOR ${ }^{5}$, Gilvan Coimbra MARTINS ${ }^{6}$
}

\section{RESUMO}

O objetivo desse trabalho foi avaliar dois métodos de laboratório para a determinação da condutividade hidráulica do solo saturada (Ko) conhecidos como Permeâmetro de carga constante (PCC) e Permeâmetro de carga decrescente (PCD), com o intuito de verificar sua aplicabilidade e variabilidade em solos amazônicos. Coletaram-se 125 amostras de solo com estrutura indeformada, através de amostrador tipo Uhland, com anéis volumétricos, de 0,072 m de altura e 0,069 m de diâmetro, devido à variabilidade apresentada pelas determinaçōes de tal parâmetro. Nos mesmos pontos de amostragens da Ko, procedeu-se coleta de anéis volumétricos para a determinação da porosidade do solo. Ainda nesses pontos foram coletadas amostras com estrutura deformada para análises físicas e químicas. Os resultados obtidos demonstram que o método do PCC foi o mais apropriado para a classe dos Latossolos estudados, apresentando os menores coeficientes de variação e desvio padrão ao longo da topossequência. Os valores de Ko estiveram distribuídos entre P1(2,65 à 3,34 cm dia-1), P2 (2,85 à 3,38 cm dia-1), P3(2,86 à 3,63 $\left.\mathrm{cm} \mathrm{dia}^{-1}\right), \mathrm{P} 4\left(2,75\right.$ à 3,49 $\left.\mathrm{cm} \mathrm{dia}^{-1}\right), \mathrm{P} 5\left(2,38\right.$ à 3,83 $\left.\mathrm{cm} \mathrm{dia}^{-1}\right)$ e P6 (2,47 à 3,52 $\left.\mathrm{cm} \mathrm{dia}^{-1}\right)$; havendo uma tendência para maiores valores de $\mathrm{K}_{\mathrm{o}}$ na superficie. A utilização de Ko como parâmetro de análise hídrica em solos porosos na superfície e muito argilosos em profundidade, como os amazônicos, necessita ser realizada com precaução, evitando a interrupção da continuidade dos poros e compactação da amostra. Mudanças na condutividade hidráulica saturada estiveram mais relacionadas a alteraçōes nas propriedades físicas do solo e posição no relevo do que nas alteraçôes das coberturas vegetais ao longo da topossequência.

PALAVRAS-CHAVE: Condutividade hidráulica saturada, carga constante, carga decrescente, solos amazônicos, topossequência

\section{Evaluation of the saturated hydraulic conductivity using two laboratory methods in a topossequence with different vegetation cover in the lower Amazon}

\begin{abstract}
The objective of this work was to evaluate two different laboratory methods for determining the saturated hydraulic conductivity (Ko), namely, the constant head permeameter method (PCC) and the falling decreasing head permeameter method (PCD) and their applicability and variability to Amazon soils. 125 undisturbed soil samples were collected with an Uhland soil sampler using volumetric rings of 0,072 $\mathrm{m}$ height and 0,069 $\mathrm{m}$ in diameter. Soil porosity was also estimated by volumetric ring samples collected at the same spots where Ko was evaluated. Disturbed soil samples were also collected for chemical and particle size analysis at the same spots. The results showed that the PCC method was more appropriate for the studied soils Oxisols, leading to the lowest coefficient of variation and standard deviation throughout the topographic sequence. The Ko values were distributed among P1(2,65 to $\left.3,34 \mathrm{~cm} \mathrm{day}^{-1}\right), \mathrm{P} 2\left(2,85\right.$ to $\left.3,38 \mathrm{~cm} \mathrm{day}^{-1}\right), \mathrm{P} 3\left(2,86\right.$ to $\left.3,63 \mathrm{~cm} \mathrm{day}^{-1}\right), \mathrm{P} 4(2,75$ to $\left.3,49 \mathrm{~cm} \mathrm{day}^{-1}\right), \mathrm{P} 5\left(2,38\right.$ to 3,83 $\left.\mathrm{cm} \mathrm{day}^{-1}\right)$ and P6 (2,47 to 3,52 $\left.\mathrm{cm} \mathrm{day}^{-1}\right)$; having a tendency to show higher Ko values at soil surface. The use of Ko as a parameter for hydraulic analysis in soils with high porosity in the surface layer and high clay content in the subsoil, as is the case in the Amazon, must be undertaken with caution to avoid compacting the sample and porous discontinuities. Throughout the studied topographic sequence, changes of saturated hydraulic conductivity were more related to changes in soil physical properties than to changes in vegetation cover throughout the studied topographic sequence.
\end{abstract}

KEY-WORDS: Saturated hydraulic conductivity; constant head permeameter; decreasing head permeameter; Amazon soils; toposequence

1 Projeto Financiado pela Fundação de Amparo a Pesquisa do Estado do Amazonas - FAPEAM, processo n 811/04

2 Aluno do Curso de Pós-graduação em Ecologia, nível doutorado - Instituto Nacional de Pesquisas da Amazônia - INPA-V8. Departamento de Ecologia, Avenida. Efigênio Sales, nº 2239, Aleixo, CEP: 69.060-020, Manaus - AM. e-mail: jdomarques@hotmail.com.Bolsista CNPq

${ }_{3}^{3}$ Pesquisador da Embrapa Amazônia Ocidental (Centro de Pesquisa Agroflorestal da Amazônia Ocidental - Manaus - AM). E-mail: lau@cpaa.embrapa.br

${ }^{4}$ Aluna do Curso de Pós-graduação em Clima e Ambiente, nível doutorado, INPA/UEA. E-mail: areisreis@hotmail.com

5 Instituto Nacional de Pesquisas da Amazônia/INPA. Laboratório Temático de Solo e Planta - LTSP. E-mail: orlando@inpa.gov.br

${ }^{6}$ Pesquisador da Embrapa Amazônia Ocidental (Centro de Pesquisa Agroflorestal da Amazônia Ocidental - Manaus - AM). e-mail: gilvan@cpaa.embrapa.br 


\section{INTRODUÇÃO}

A condutividade hidráulica saturada do solo (Ko) representa um parâmetro chave para análise da intensidade do deslocamento da água no solo. Para a sua determinação existe uma grande variedade de métodos, com diferentes níveis de precisão; alguns aplicáveis apenas em determinadas condiçōes ou com certos objetivos, os quais, de modo geral, podem ser agrupados em métodos indiretos ou diretos. Os métodos indiretos relacionam a condutividade hidráulica com propriedades do solo (distribuição do tamanho dos poros, textura, porosidade drenável, densidade do solo, etc.). Nos métodos diretos, a Ko pode ser determinada em condiçōes de laboratório e campo, ressaltando-se neste trabalho, os métodos de laboratório. Klute \& Dirksen (1986), salientam como os métodos de laboratório mais utilizados os permeâmetros de carga constante e carga decrescente, os quais fornecem resultados aproximados sendo recomendados quando os de campo são impraticáveis. Alguns trabalhos relatam a grande variabilidade de Ko, entre esses Vieira et al. (1981); Bouma et al. (1989) e Teixeira (2001). A síntese desses trabalhos leva a concluir que as propriedades hídricas do solo medidas sob condição de saturação como a condutividade hidráulica saturada, capacidade de infiltração ou umidade de saturação têm variabilidade muito alta. Estudo comparativo entre os métodos de carga constante (laboratório) e permeametro de guelph (campo) foram realizados como forma de testar a veracidade e variabilidade dos dados (Mohanty et al., 1994); entretanto sendo importante uma análise sobre métodos de laboratório utilizando amostras indeformadas em solos amazônicos. É comum encontrar em artigos na ciência do solo (Pedrotti, 2003; Argenton, 2005 entre outros) valores de (Ko) com um parâmetro hídrico utilizado para caracterização de solos. Nesse sentido, surge o questionamento: até que ponto os métodos utilizados em laboratório e valores de Ko obtidos são confráveis? Discute-se nesse trabalho a aplicação de dois métodos de laboratório e o pressuposto teórico quanto à recomendação para análise da Ko.

Assim, o presente estudo compara dois métodos de laboratório para determinação da condutividade hidráulica saturada quanto a aplicabilidade para solos amazônicos e variabilidade dos valores obtidos em função de atributos do solo e sistema de uso da terra.

\section{MATERIAL E MÉTODOS}

\section{CARACTERIZAÇÃO DA ÁREA EXPERIMENTAL}

O presente trabalho foi conduzido em uma topossequência de solos, situada no Município de Parintins (Figura 1), com coordenadas geográficas (P1 02²6 $45^{\prime \prime} \mathrm{S}$ e $\left.56^{\circ} 26^{\prime} 53^{\prime \prime} \mathrm{W}\right)$, (P2 $02^{\circ} 26^{\prime} 57^{\prime \prime} \mathrm{S}$ e $\left.56^{\circ} 26^{\prime} 51^{\prime \prime} \mathrm{W}\right),\left(\mathrm{P} 302^{\circ} 27^{\prime} 07^{\prime \prime} \mathrm{S}\right.$ e $\left.56^{\circ} 26^{\prime} 54^{\prime \prime} \mathrm{W}\right)$, (P4 02 $27^{\prime} 07^{\prime \prime}$ S e $\left.56^{\circ} 26^{\prime} 53^{\prime \prime W}\right)$ e (P5 02 $27^{\circ} 05^{\prime \prime} S$ e $\left.56^{\circ} 26^{\prime} 57^{\prime \prime} \mathrm{W}\right)$ apresentando diferentes coberturas vegetais (floresta densa, capoeira com sete anos, capoeira com 1 ano e floresta aberta) e variações na textura, densidade, porosidade e na química do solo, em função da posição na paisagem (Figura 2), Segundo a classificação de Koppen o clima da região pode ser classificado como Afi, caracterizado por apresentar precipitação média anual de $2420 \mathrm{~mm}$, com $295 \mathrm{~mm}$ mensais, de março a abril, e $105 \mathrm{~mm}$ mensais, de agosto a setembro (EMBRAPA, 1984).

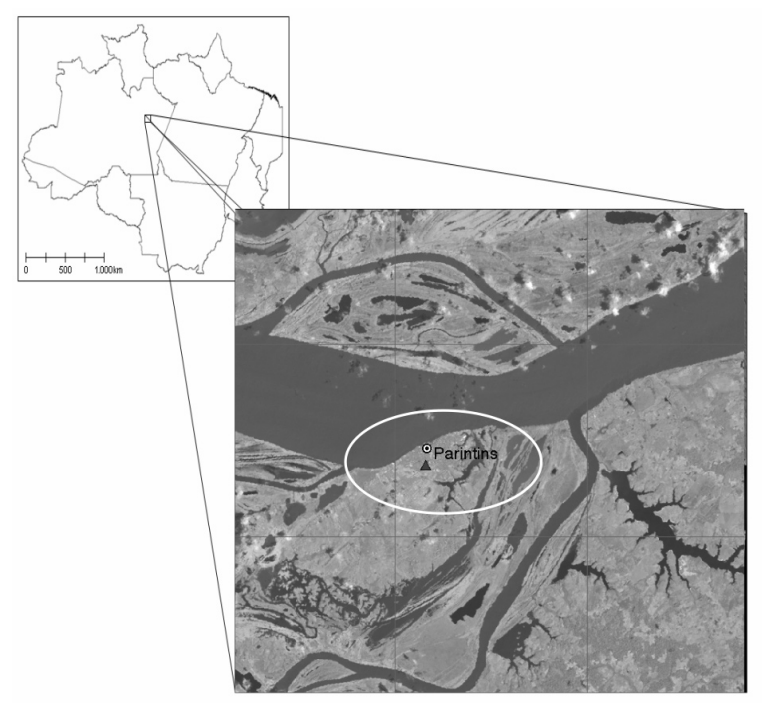

Figura 1 - Amazônia Legal (mapa acima) e localização da área estudada. FONTE: SIPAM/2005

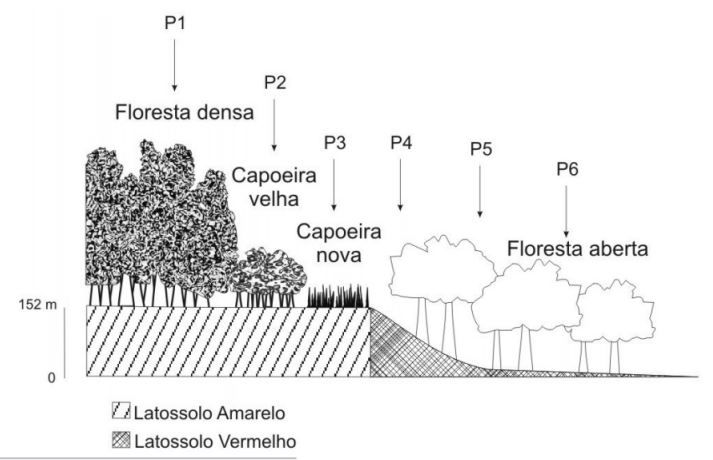

Figura 2 - Esquema demonstrativo das classes de solos e cobertura vegetal predominante na topossequência

\section{AMOSTRAGEM DO SOLO E DETERMINAÇÕES}

Foram abertos seis perfis de solo, ao longo da topossequência, com dimensão de $1,5 \mathrm{~m} \times 1,5 \mathrm{~m} \times 1,5 \mathrm{~m}$ para a descrição morfológica (Lemos \& Santos, 1996), classificação de solos (EMBRAPA, 1999a), caracterização física, química e hídrica do solo (Ko). Foram coletadas amostras com estrutura deformada ao longo dos horizontes pedogenéticos identificados; para as determinações físicas e químicas até $1,5 \mathrm{~m}$ de profundidade. A densidade do solo $(\rho)$ foi determinada a partir de amostras indeformadas, utilizando anéis volumétricos. A determinação 
da densidade de partículas foi realizada pelo método do picnômetro conforme metodologia descrita no manual de métodos de análise físicas da EMBRAPA (1997).

Para o estudo da condutividade hidráulica do solo saturada (Ko) foram utilizadas amostras com estrutura indeformada, sendo coletado um total de 125 amostras, nos horizontes pedológicos, com cinco repetiçôes. Foi utilizado um amostrador de solo tipo Uhland, com anéis volumétricos, de $0,072 \mathrm{~m}$ de altura e $0,069 \mathrm{~m}$ de diâmetro. Após as coletas esses anéis foram acondicionados em papel alumínio para evitar perdas de umidade, sendo preparados no laboratório. Nos mesmos pontos de amostragens da Ko, foram coletadas amostras utilizando-se anéis volumétricos com $0,005 \mathrm{~m}$ de altura e diâmetro, para a determinação da porosidade do solo (macroporos e microporos), através da determinação da retenção de água no solo e utilização da equação da porosidade.

No laboratório, procedeu-se o processo de saturação utilizando água destilada e desaerada, aplicada com gotejador de Mariotte, levando no mínimo 24 horas para a completa saturação. Após saturadas, as amostras foram retiradas da bandeja e encaixadas nos dispositivos construídos para evitar perda de água. Em seguida, o módulo de carga constante (Figura 3) primeiro a ser testado, recebeu as amostras no intuito de manter os poros saturados. Após as avaliaçōes pelo método de carga constante as amostras foram novamente saturadas para serem submetidas ao módulo destinado a carga decrescente (Figura 4).

A análise granulométrica foi realizada pelo método da pipeta (EMBRAPA, 1997). Foram utilizadas $50 \mathrm{~g}$ de solo dispersando-o com solução aquosa de pirofosfato de sódio

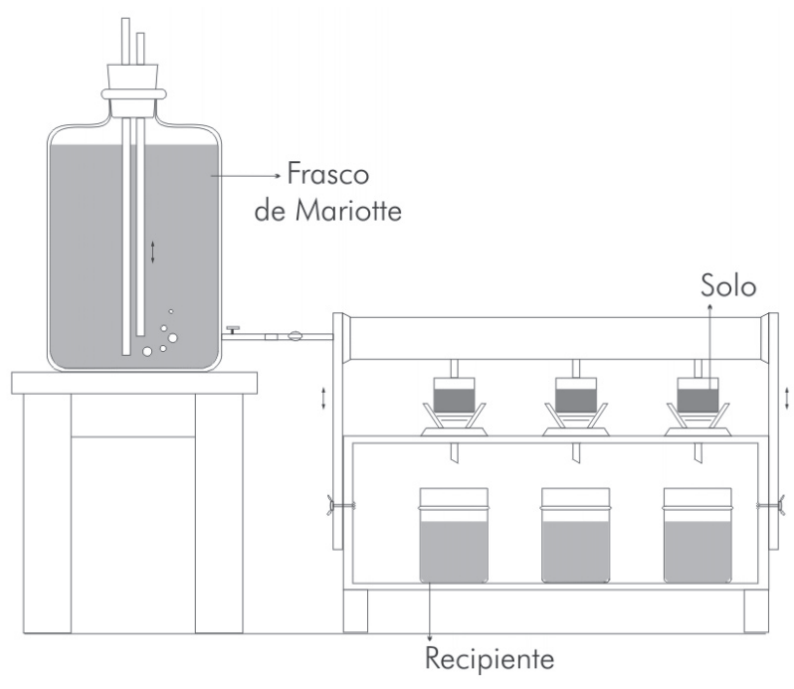

Figura 3 - Desenho esquemático do módulo do permeâmetro de carga constante utilizado na determinação da condutividade hidráulica do solo saturado puro $\left(6 \mathrm{~kg} \mathrm{~m}^{-3}\right)$ e de hidróxido de sódio $\left(4 \mathrm{~kg} \mathrm{~m}^{-3}\right)$ por agitação lenta durante 16 horas. As fraçōes grosseiras (areia fina e grossa) foram separadas por tamisação, secas em estufa e pesadas para obtenção dos respectivos percentuais. $\mathrm{O}$ teor de silte corresponde ao complemento dos percentuais para $100 \%$, sendo obtido por diferença das outras frações em relação a amostra original.

As características químicas foram estudadas com base nas análises de: $\mathrm{pH}$ em água, fósforo, potássio, cálcio, magnésio, alumínio, carbono, nitrogênio, ferro, zinco, mangânes, cobre e matéria orgânica, seguindo a metodologia descrita por EMBRAPA (1999b).

\section{DETERMINAÇÃO DA CONDUTIVIDADE HIDRÁULICA SATURADA EM LABORATÓRIO - VANTAGENS E DESVANTAGENS}

Fluxo em solo saturado e não saturado representam as formas de estudar o fluxo de água no solo. A realização de estudos hídricos favorece informaçōes importantes da velocidade com que a água se movimenta no solo, sendo aplicado para um melhor manejo e uso do solo de uma região. Apesar da aplicabilidade dos métodos para a determinação de Ko em laboratório, alguns fatores são considerados desvantajosos, como a sua grande variabilidade (Van Es et al., 1999; Marques, 2004) e procedimentos metodológicos de laboratório durante a determinação (Bagarello, 1996), dificultando a determinação de um valor representativo para uma área e até em horizontes ao longo do perfil do solo. Além

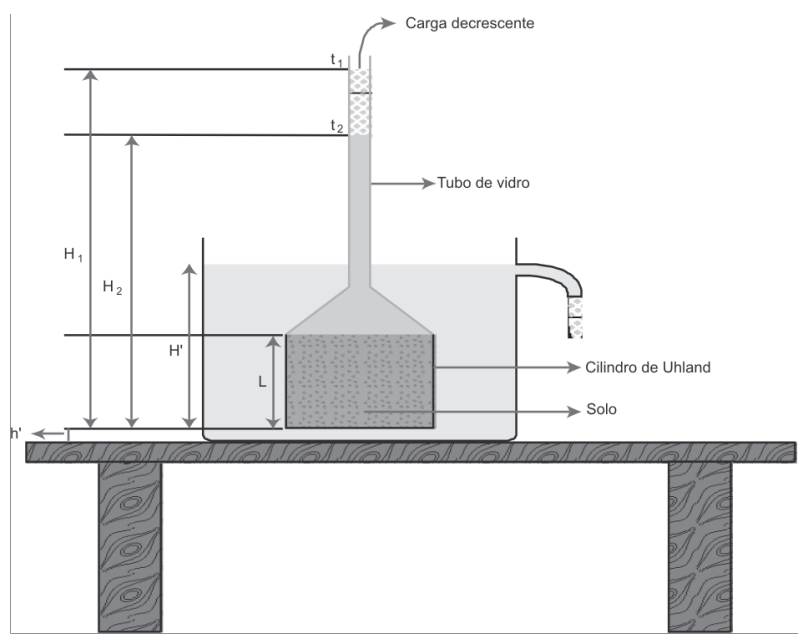

Figura 4 - Desenho esquemático do permeâmetro de carga decrescente utilizado na determinação da condutividade hidráulica do solo saturado (Marques, et al., 2004 adaptado de Libardi, 2000)

sendo:

$\Delta \mathrm{t}=\mathrm{t}_{2}-\mathrm{t}_{1}$ intervalo de tempo para o nível de água no tubo de vidro cair de $\mathrm{H}_{1}$ para $\mathrm{H}_{2}$; $\mathrm{A}=$ área da secão transversal da coluna de solo;

$\mathrm{A}=$ a a comprimento da amostra de solo;

$\mathrm{a}=$ área da seção transversal do tubo de vidro onde se mede $\mathrm{H}$;

$\mathrm{H}_{1}$ e $\mathrm{H}_{2}$ representam potenciais totais da amostra, os quais foram fixados em dois pontos no tubo e mantidos constantes ao longo das medições; $\mathrm{H}^{\prime}=$ carga hidráulica na superfície da amostra.

h' = nível de referência 
disso, em muitas situações, o interesse é quantificar o fluxo em condição não saturada, situação mais comum na natureza. Nesse caso, a condutividade hidráulica passa a ser uma função direta da umidade do solo $(\theta)$, isto é, $K=K(\theta)$.

Conforme a literatura (Gardner, 1986; Libardi, 2000), os permeâmetros de carga constante, aparelhos utilizados para determinação da condutividade hidráulica do solo saturada (Ko), são recomendados para solos que apresentam alto Ko, enquanto que os de carga decrescente são descritos como adequados para solos com baixo Ko. Uma questão a ser discutida está relacionada à confiabilidade de aplicação dos dois métodos de determinação de Ko no laboratório para solos argilosos e porosos como os selecionados neste estudo. Qual o método mais apropriado e quais fatores físicos e hídricos interferem na sua aplicação? Ou ainda, as diferentes coberturas vegetais influenciam nos valores obtidos?

\section{PERMEÂMETRO DE CARGA CONSTANTE (PCC)}

$\mathrm{O}$ método do permeâmetro de carga constante segundo (Youngs, 1991) foi determinado a partir da condução das amostras a um sistema montado para a determinação da condutividade hidráulica do solo saturada (Figura 3). $\mathrm{O}$ método consistiu basicamente em manter uma carga hidráulica constante, utilizando-se um Frasco de Mariotte, medindo o volume da solução drenado em função do tempo, isto é, a vazão $(\mathrm{Q})$. A massa de água que passava em um tempo pré-determinado era determinada em uma balança digital, considerando-se o equilíbrio após três medidas próximas consecutivas apresentarem valores próximos.

Partindo da equação de Darcy: $Q=K A \frac{h_{1}-h_{2}}{L}$

onde $\left(h_{1}-h_{2}\right)$ é a diferença de carga piezométrica; $A$ é a área da secção transversal e $L$ o comprimento do filtro que contem a amostra; e $\mathrm{C}$ a condutividade hidráulica.

Sendo $h_{1}=\phi_{1}$ e $h_{2}=\phi_{2}, z_{1}-z_{2}=L$ tem-se:

$Q=K A\left(\frac{\phi_{1}-\phi_{2}}{z_{1}-z_{2}}\right)=K A\left(\frac{\Delta \phi}{\Delta z}\right) ;$ sendo $\mathrm{q}=\mathrm{Q} / \mathrm{A}$

reescrevendo na direção vertical, através do meio poroso:

$\vec{q}=-K\left(\frac{\partial \phi}{\partial z}\right) \hat{k}$

da equação de Darcy-Buckinghan para solo saturado:

$\overrightarrow{q_{0}}=-K_{0}\left(\frac{\partial \phi}{\partial z}\right) \hat{k}$ sabendo que a substituição da equação $\mathrm{a}=0$ e b $=\mathrm{h}+\mathrm{L} / \mathrm{L}$ na equação: $\phi_{t} \equiv a \pm b z$; tem-se a solução de equilíbrio de Laplace:

$\phi_{t} \equiv\left(\frac{h \pm L}{L}\right) z$

derivando: $\frac{\partial \phi t}{\partial z} \equiv \frac{h \pm L}{L}$

substituindo (6) em (4) temos o módulo:

$q_{0} \equiv K_{0} \frac{C+L}{L}$

Sabendo que $q \equiv \frac{V}{\Delta t}$

e substituindo (8) em (7): $\frac{V}{\Delta t} \equiv K_{0}\left(\frac{C+L}{L}\right)$

Assim, reagrupando, $K_{0}$ foi calculada pela seguinte expressão: $K_{o}=\frac{V_{A} \cdot L}{A \cdot t(h+L)}$

\section{PERMEÂMETRO DE CARGA DECRESCENTE (PCD)}

O permeâmetro de carga decrescente (Youngs, 1991) foi determinado com a inserção das amostras de solo em um dispositivo previamente construído composto por um tubo de vidro transparente colocado em um módulo de encaixe (Figura 4). Antes do início das medidas foram delimitados dois pontos no tubo de vidro (Figura 4) denominados de $\mathrm{H}_{1}$ e $\mathrm{H}_{2}$ de forma que fosse possível acompanhar os seus respectivos tempos $\left(\mathrm{t}_{1}\right.$ e $\left.\mathrm{t}_{2}\right)$. A partir do momento que o nível da coluna de água ultrapassava o ponto $\mathrm{H} 1$, o cronômetro era acionado pra verificar o tempo gasto para a água ultrapassar o volume de solo amostrado. Com a chegada da coluna no ponto $\mathrm{H} 2$, tinha-se o intervalo de tempo gasto para o deslocamento da água ao longo do sistema.

Partindo da equação: $q=\frac{\Delta V}{\Delta t}=\frac{\Delta L}{\Delta t}=\frac{\Delta\left(\frac{V}{A}\right)}{\Delta t}=\frac{1}{A} \frac{d V}{d t}$

$q=\frac{1}{A} \frac{d V}{d t}$ e $\quad q=K_{o} \frac{H}{L}$

derivando: $\frac{d V}{d t}=K_{o} \frac{H}{L} \rightarrow \frac{d V}{d t}$;

obtem-se: $\frac{d V}{d t}=K_{o} A \frac{H}{L}$

volume total: $d V=$ a.d.H $\rightarrow \frac{d V}{d t}=\frac{a d H}{d t}$

igualando (12) e (13)

$\frac{a d H}{d t}=K_{o} A \frac{H}{L}$ 
$-\frac{d H}{H}=\frac{K_{o} A}{a L} d t$

Integrando-se ambos os lados tem-se: $-\int \frac{d H}{H}=\frac{K_{o} A}{a L} \int_{i o}^{t} d t$

$-[\ln H]_{a}^{b}=\frac{K_{o} A}{a L}(t-t o)$

$-\ln \left(\frac{b}{a}\right)=\frac{K_{o} A}{a L} \Delta t$ tem-se

Considerando $\left\{\begin{array}{l}a=H_{1}-H^{\prime} \\ b=H_{2}-H^{\prime}\end{array}\right\}$ e substituindo na equação (18);

$-\ln \left(\frac{H_{2}-H^{\prime}}{H_{1}-H}\right)=\frac{K_{o} A}{a L} \Delta t$

rearranjando: $-\ln \left(\frac{H_{2}-H^{\prime}}{H_{1}-H}\right) a L=K_{o} A(\Delta t)$. Assim, reagrupando, $\mathrm{K}_{\mathrm{o}}$ foi calculada pela seguinte equação:

$K_{。}=\frac{a L}{A \Delta t} \ln \left[\frac{H_{1}-H^{\prime}}{H_{2}-H^{\prime}}\right]$

\section{ANÁLISE DOS DADOS}

A distribuição da condutividade hidráulica é normalmente do tipo log-normal (Logsdon \& Jaynes, 1996), tendo sido comprovada neste estudo com aplicação do teste de normalidade (Kolmogorov-Smirnov). A média da condutividade hidráulica saturada em cada seçáo do perfil estudado foi obtida a partir da média aritmética após a transformação logarítmica dos dados, aplicando-se o teste de Tukey $5 \%$ de probabilidade para comparar os métodos.

A análise do comportamento hidráulico no solo foi realizada com o auxilio de análise de variância (teste F), desvio padrão e separação de diferenças entre os valores médios de Ko para cada método. As análises estatísticas foram efetuadas com a utilização do Programa Systat 8.0 (Wikinson, 1998).

\section{RESULTADOS E DISCUSSÃO}

\section{ATRIBUTOS FÍSICOS E QUIIMICOS NA TOPOSSEQUÊNCIA DE SOLOS}

As Tabelas 1 e 2 apresentam os resultados das análises físicas e químicas dos solos ao longo da topossequência. A análise granulométrica (Tabela 1) revelou heterogeneidade na distribuição do tamanho das partículas, havendo um aumento do teor de argila com a profundidade em todos os perfis estudados, estando os valores compreendidos nos horizontes entre LAd-P1(831 $\mathrm{g} \mathrm{kg}^{-1}$ a $\left.920 \mathrm{~g} \mathrm{~kg}^{-1}\right)$, LAd-P2 $\left(745 \mathrm{~g} \mathrm{~kg}^{-1}\right.$ a $\left.910 \mathrm{~g} \mathrm{~kg}^{-1}\right)$, LAd-P3 $\left(602 \mathrm{~g} \mathrm{~kg}^{-1}\right.$ a $\left.870 \mathrm{~g} \mathrm{~kg}^{-1}\right)$, LVd-P4 (314 $\mathrm{g} \mathrm{kg}^{-1}$ a $\left.706 \mathrm{~g} \mathrm{~kg}^{-1}\right)$, LVda-P5 (298 $\mathrm{g} \mathrm{kg}^{-1}$ a $\left.653 \mathrm{~g} \mathrm{~kg}^{-1}\right)$, LVd-P6 (342 $\mathrm{g} \mathrm{kg}^{-1}$ a $\left.421 \mathrm{~g} \mathrm{~kg}^{-1}\right)$; sendo classificados como de textura argilosa nos horizontes dos Latossolos Amarelos e textura média na superfície do Latossolo Vermelho argissólico e Latossolo Vermelho, evoluindo para argilosa e muito argilosa, nas profundidades elevadas (Tabela 3). Os valores de densidade do solo $(\rho)$ apresentaram comportamento similar ao da textura, com aumento em profundidade, sendo os menores valores encontrados nas camadas superficiais dos solos sob ambiente de floresta aberta (Tabela 1).

O teor de matéria orgânica decresce em profundidade (Tabela 2), sendo o seu maior conteúdo encontrado na superfície devido à incorporação de resíduos vegetais no solo, refletindo nos maiores valores de fósforo e soma de bases na superfie. A diminuição da matéria orgânica em profundidade deve ser um dos fatores que interferem nos valores de densidade do solo (Tabela 1). A capacidade de troca de cátions ( $\mathrm{T}$ ) decresceu em profundidade em todos os perfis (Tabela 2). Ainda na Tabela 2, observa-se baixa saturação por base (V\%) e alta saturação por alumínio (m), fato comum em solos originados desses sedimentos argilosos.

\section{COMPARAÇÃO DOS MÉTODOS DE LABORATÓRIO ESTUDADOS}

As Tabelas 4 e 5 apresentam os resultados de Ko e log Ko pelos métodos de carga constante (PCC) e carga decrescente (PCD), respectivamente. Analisando os valores médios obtidos de Ko ao longo da topossequência de solos (Tabela 5), percebe-se que houve diferença significativa entre os métodos utilizados. Os valores de log Ko estiveram distribuídos entre P1 (2,65 à $3,34 \mathrm{~cm} \mathrm{dia}^{-1}$ PCC; 1,86 à $\left.2,89 \mathrm{~cm} \mathrm{dia}^{-1} \mathrm{PCD}\right)$, P2 (2,85 à $3,38 \mathrm{~cm} \mathrm{dia}^{-1}$ PCC; 2,13 à $\left.2,91 \mathrm{~cm} \mathrm{dia}^{-1} \mathrm{PCD}\right)$, P3 (2,86 à 3,63 $\mathrm{cm} \mathrm{dia}^{-1}$ PCC; 2,03 à $\left.2,93 \mathrm{~cm} \mathrm{dia}^{-1} \mathrm{PCD}\right)$, P4(2,75 à $3,49 \mathrm{~cm} \mathrm{dia}^{-1}$ PCC; 1,78 à $\left.2,95 \mathrm{~cm} \mathrm{dia}^{-1} \mathrm{PCD}\right)$, P5(2,38 à $3,83 \mathrm{~cm} \mathrm{dia}^{-1}$ PCC; 1,82 à $3,02 \mathrm{~cm} \mathrm{dia}^{-1} \mathrm{PCD}$, P6 (2,47 à $3,52 \mathrm{~cm} \mathrm{dia}^{-1}$ PCC; 1,86 à $3,10 \mathrm{~cm} \mathrm{dia}^{-1}$ PCD. Teixeira (2001) estudando os efeitos do uso da terra sobre as propriedades hidráulicas do solo, por métodos de campo, e em pontos de amostragens pertencentes à classe de Latossolos Amarelos na Amazônia encontrou valores da $\mathrm{K}_{\mathrm{o}}$ na ordem de $6,62 \mathrm{~cm} \mathrm{dia}^{-1}$ a $8,41 \mathrm{~cm} \mathrm{dia}^{-1}$. A diferença quando comparada com os encontrados neste estudo pode estar relacionada a vários fatores como: pontos de amostragem e distribuição das raízes (Tabela 5), demonstrando a grande variabilidade dessa propriedade $\mathrm{O}$ mesmo autor, utilizando o infiltrômetro de tensão, ainda descreve valores de $\mathrm{K}_{\mathrm{o}}$ variando de 2,60 $\mathrm{cm} \mathrm{dia}^{-1}$ à $4,74 \mathrm{~cm} \mathrm{dia}^{-1}$. Marques (2004) estudando parâmetros hídricos na mesma classe de solos sob sistema agroflorestal na Amazônia, encontrou valores com variações de 2,62 $\mathrm{cm} \mathrm{dia}^{-1}$ à $3,20 \mathrm{~cm} \mathrm{dia}^{-1}$ e variaçôes de 1,93 à 3,22 $\mathrm{cm} \mathrm{dia}{ }^{-1}$ em Latossolo Vermelho. No geral, os dois métodos de laboratório, aqui considerados, não apresentaram elevados coeficientes de variação $(\mathrm{CV})$ e desvio padrão, o que torna segundo alguns autores, um dos principais inconvenientes para a utilização desses métodos como parâmetro hidráulico, já que em alguns estudos é comum variações na ordem de 52\%, 1000\% e 3300\% (Warrick \& Nielsen, 1980; Anderson $\&$ Cassel, 1986). A variabilidade e desvios padrões obtidos 
deve envolver procedimentos no campo e no laboratório, conforme ressaltam, (Warrick \& Nielsen, 1980; Field, 1984) e devido aos ambientes amostrados.

No decorrer da execução dos métodos, observou-se algumas diferenças de Ko para amostras pertencentes a mesma seção de amostragem, comprovando a dificuldade existente nas determinaçōes dessa propriedade. Entretanto, analisando os valores das dez leituras realizadas em cada repetição não demonstraram discrepâncias acentuadas nos valores, evidenciando que os métodos não apresentaram fonte de erro que possam ter interferido na análise dos resultados.

A ordem de grandeza dos dados de Ko pelos dois métodos foram diferentes, havendo contraste entre si (Tabela 5). O método do PCC demonstrou ao longo das determinaçōes valores de Ko maiores que o PCD, entretanto, em algumas comparaçôes não significativo. (Tabela 5). Um dos pontos observados durante a utilização do PCC está relacionado a manutenção da carga hidráulica sobre a amostra. Como as amostras tendem a apresentar fluxos diferentes, torna-se difícil, a constância da carga igual para módulos com capacidade para 5 amostras, exceto em sistemas com controle da saída de água. Primeiramente, utilizou-se um permeâmetro para três amostras (Figura 3), reduzindo-o a seguir para 1 amostra (Figura 5), devido a ocorrência de fluxo diferente apresentado pelas amostras e a dificuldade de se manter um nível constante. No caso do PCD, o inconveniente apresentado está relacionado ao manuseio da amostras, já que foi necessário movimentar o modulo elaborado com mais constância para o início das leituras.

A premissa da escolha do método PCC ou PCD pelo pressuposto teórico solos com baixa e alta condutividade foi constatada, tendo sido o método do PCC o mais indicado

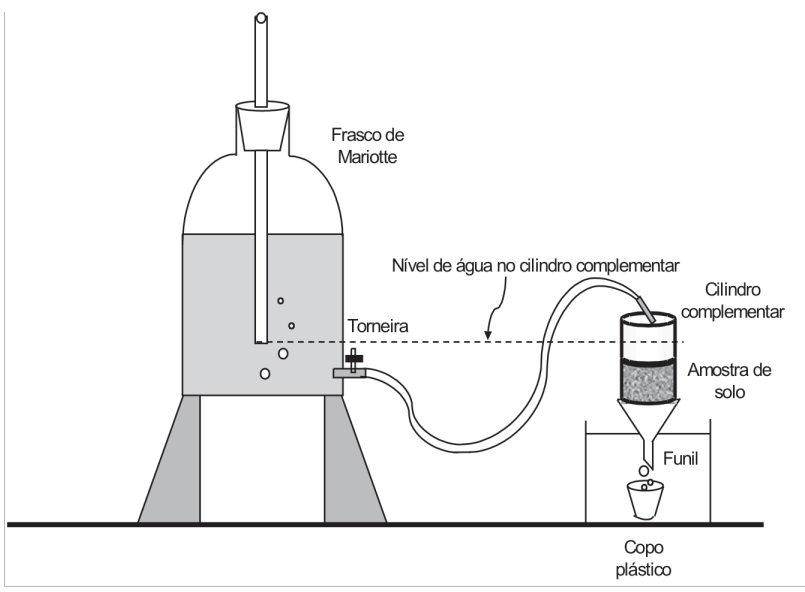

Figura 5 - Desenho esquemático do permeâmetro de carga constante para uma amostra utilizado na determinação da condutividade hidráulica do solo saturado (Fonte: Teixeira, 2005) para as classes de Latossolos Amarelos Distrófico, Latossolo Vermelho Distrófico, Latossolo Vermelho Distrófico argissólico identificados ao longo da topossequência, apresentando baixo CV e desvio padrão (Tabela 5).

\section{ESPAÇO POROSO NA DETERMINACAO DE KO EM SOLOS AMAZÔNICOS VS VARIAÇÕES DOS AMBIENTE AO LONGO DA TOPOSSEQUÊNCIA}

Possíveis problemas quanto à relação da porosidade vs Ko é constatada na Figura $8 \mathrm{~A}$ à F, observando-se que sensíveis variaçóes na macroporosidade promove mudanças em Ko, havendo uma tendência para maiores valores de $\mathrm{K}_{\mathrm{o}}$ na superfície, relacionando-se com maiores valores de macroporos (Tabela 1).

Outros parâmetros físicos foram observados, evidenciando que nesses solos, a densidade e o teor de argila são inversamente proporcionais a Ko. Isso permiti inferir que compactação durante a amostragem em solos argilosos e muito argilosos como os aqui estudados (Tabela 3) pode alterar os resultados obtidos, pois Ko também apresentou relação direta com a densidade do solo (Figura $8 \mathrm{~A}$ à F).

A forma e a continuidade dos poros em superfície (Tabela 1) podem conduzir a erros de amostragem com cilindros pequenos nesses solos, já que os anéis podem ficar dispostos em pontos com alta, baixa ou sem a presença de poros com diâmetros grandes, influenciando nas variaçôes de Ko (Figura 7) (Tabela 5). Um outro fator que deve ser salientado no estudo de Ko em solos argilosos e porosos como os amazônicos é o tamanho do cilindro volumétrico de forma a apresentar um número representativo dos poros de cada horizonte. A situação de amostras na superfície com grande índice radicular (Tabela 3) surge como outro inconveniente, pois a continuidade vertical dos macroporos deve ser observada. Nessa profundidade ocorre um maior índice de raízes pequenas finas (Tabela 3) que contribuem com translocação da $\mathrm{MO}$ em profundidade e estruturação do solo (Gonçalves \& Mello, 2000) .

Um procedimento a ser considerado para uma melhor quantificação de Ko em sistemas com macroporos, como os amazônicos, é a coleta de amostras em cilindros grandes ou a determinação direta no campo, minimizando as influências negativas que pequenas amostras exercem na determinação desse parâmetro.

Analisando os dados de Ko em função da cobertura vegetal, observam-se maiores valores no sistema de floresta aberta (8 $\mathrm{D}, \mathrm{E}$ e F) (figura 8), desenvolvidos sobre solos com textura média e maiores porosidades. Nota-se na Tabela 1 que o teor de argila foi a propriedade física que contribuiu para que Ko capoeira nova $(8 \mathrm{C})>$ Ko capoeira 7 anos $(8 \mathrm{~B})>$ Ko floresta densa (8A). Apesar da textura em todos os horizontes desses sistemas serem muito argilosa (Tabela 3), Ko foi sensível a 

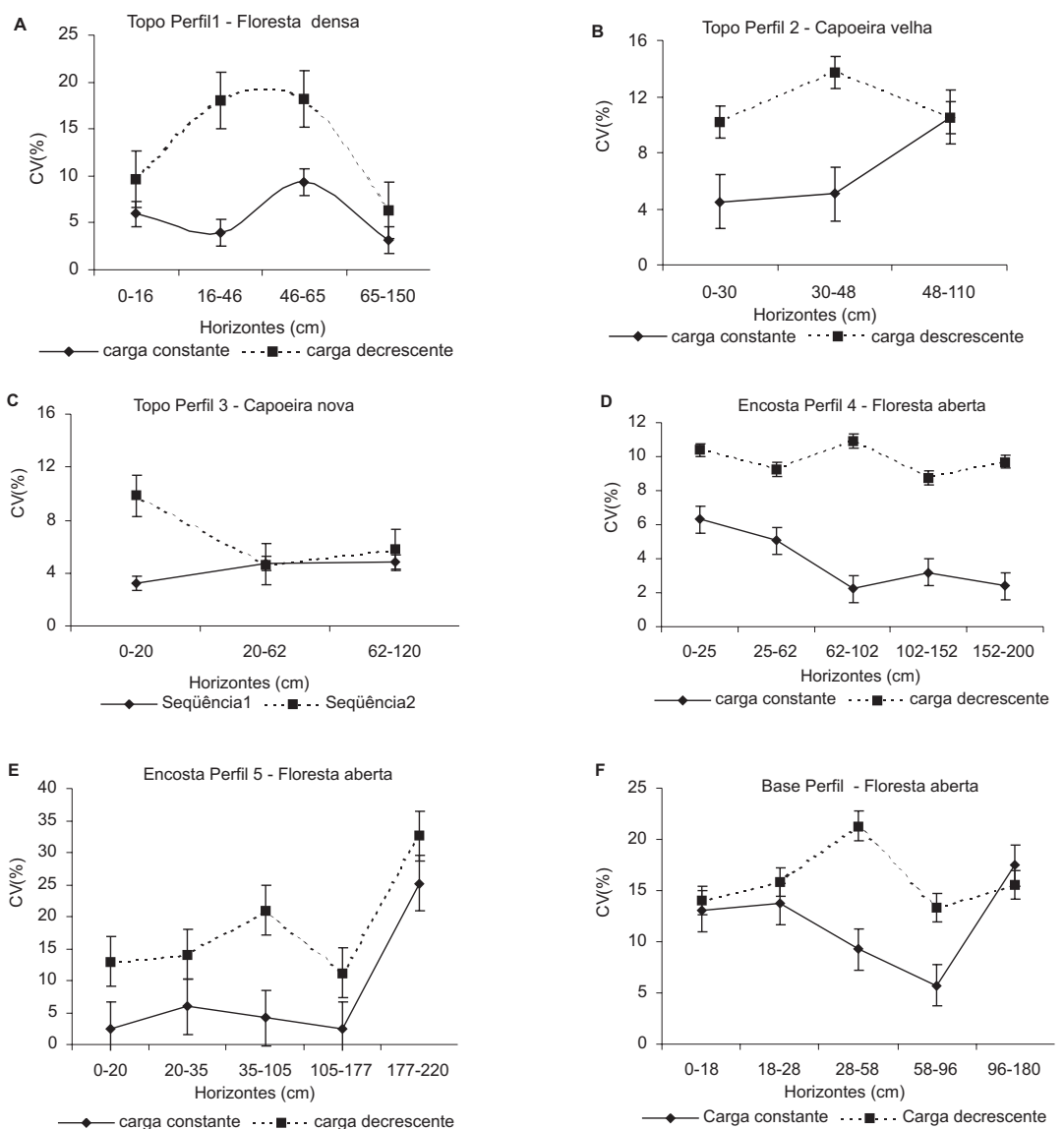

Figura 6 - Gráfico demonstrativo do comportamento coeficiente de variação pelos dois métodos utilizados

Tabela 1 - Distribuição granulométrica, densidade dos sólidos e do sol o, porosidade nos horizontes dos perfis da topossequência, Serra de Parintins-AM.

\begin{tabular}{|c|c|c|c|c|c|c|c|c|c|c|c|c|c|c|}
\hline \multirow{2}{*}{$\begin{array}{l}\text { Prof. } \\
\text { (m) }\end{array}$} & \multirow{2}{*}{ Hor } & \multicolumn{3}{|c|}{ Areia } & \multirow{2}{*}{ Silte } & \multirow{2}{*}{$\begin{array}{c}\text { Argila } \\
\text { Total }\end{array}$} & \multirow{2}{*}{$\rho$} & \multirow{2}{*}{$\rho_{\mathrm{s}}$} & \multicolumn{3}{|c|}{ Porosidade } & \multirow[t]{2}{*}{$\mathrm{N}$} & C & \multirow[t]{2}{*}{$\mathrm{C} / \mathrm{N}$} \\
\hline & & Grossa & Fina & Total & & & & & Total & $\mathrm{Ma}$ & Mi & & $--\%$ & \\
\hline & & \multicolumn{3}{|c|}{ 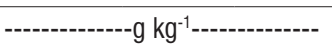 } & $----g ~ k g$ & ----- & \multicolumn{5}{|c|}{ 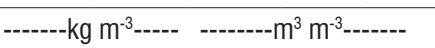 } & & & \\
\hline \multicolumn{15}{|c|}{ P1 - LAd - Latossolo Amarelo Distrófico - Floresta Densa - Platô } \\
\hline $0,00-0,16$ & $\mathrm{~A} 1$ & 10,8 & 8,68 & 19,48 & 149,53 & 831 & 670 & 2320 & 0,71 & 0,35 & 0,36 & 0,11 & 2,08 & 18,90 \\
\hline $0,16-0,46$ & $A B$ & 8,24 & 9,22 & 17,46 & 129,53 & 853 & 900 & 2470 & 0,63 & 0,25 & 0,38 & 0,22 & 3,91 & 17,77 \\
\hline $0,46-0,65$ & Bw1 & 7,84 & 7,84 & 15,68 & 97,33 & 887 & 1040 & 2470 & 0,58 & 0,18 & 0,40 & 0,12 & 2,05 & 17,08 \\
\hline $0,65-1,50+$ & Bw2 & 9,76 & 5,19 & 14,95 & 65,05 & 920 & 1130 & 2500 & 0,55 & 0,14 & 0,41 & 0,21 & 2,83 & 13,47 \\
\hline \multicolumn{15}{|c|}{ P2 - LAd - Latossolo Amarelo Distrófico - Capoeira velha 7 anos - Platô } \\
\hline $0,00-0,30$ & $\mathrm{~A} 1$ & 126,40 & 12,48 & 138,88 & 116,12 & 745,00 & 782 & 2708 & 0,71 & 0,32 & 0,38 & 0,21 & 3,05 & 14,31 \\
\hline $0,30-0,48$ & $A B$ & 17,91 & 9,41 & 27,32 & 232,18 & 740,50 & 1025 & 2601 & 0,60 & 0,21 & 0,39 & 0,11 & 1,95 & 17,59 \\
\hline $0,48-1,10^{+}$ & Bw1 & 21,16 & 10,07 & 31,23 & 58,77 & 910,00 & 1001 & 2587 & 0,61 & 0,24 & 0,36 & 0,06 & 0,85 & 12,72 \\
\hline \multicolumn{15}{|c|}{ P3 - LAd - Latossolo Amarelo Distrófico - Capoeira nova (3 anos) - Platô } \\
\hline $0,00-0,20$ & $\mathrm{~A} 1$ & 64,98 & 73,84 & 138,82 & 258,69 & 602,50 & 800 & 2760 & 0,65 & 0,30 & 0,35 & 0,18 & 2,99 & 16,61 \\
\hline $020-0,62$ & $A B$ & 18,10 & 7,20 & 25,30 & 314,70 & 660,00 & 1060 & 2500 & 0,60 & 0,20 & 0,40 & 0,10 & 1,76 & 17,60 \\
\hline $0,62-1,20^{+}$ & Bw1 & 12,00 & 16,45 & 28,45 & 101,55 & 870,00 & 1000 & 2480 & 0,50 & 0,20 & 0,30 & 0,07 & 0,70 & 10,00 \\
\hline \multicolumn{15}{|c|}{ P4 - LVd -Latossolo Vermelho Distrófico - Floresta aberta - Encosta } \\
\hline $0,00-0,25$ & A1 & 160,17 & 108,19 & 268,36 & 417,64 & 314,00 & 454 & 2577 & 0,82 & 0,48 & 0,33 & 0,67 & 7,80 & 11,54 \\
\hline $0,25-0,60$ & $\mathrm{~A} 2$ & 79,10 & 66,43 & 145,53 & 427,97 & 426,50 & 457 & 2730 & 0,83 & 0,47 & 0,36 & 0,56 & 7,71 & 13,74 \\
\hline
\end{tabular}


Tabela 1 - Continuação

\begin{tabular}{|c|c|c|c|c|c|c|c|c|c|c|c|c|c|c|}
\hline \multirow{2}{*}{$\begin{array}{l}\text { Prof. } \\
\text { (m) }\end{array}$} & \multirow{2}{*}{ Hor } & \multicolumn{3}{|c|}{ Areia } & \multirow{2}{*}{ Silte } & \multirow{2}{*}{$\begin{array}{c}\text { Argila } \\
\text { Total }\end{array}$} & \multirow{2}{*}{$\rho$} & \multirow{2}{*}{$\rho_{\mathrm{s}}$} & \multicolumn{3}{|c|}{ Porosidade } & N & C & $\mathrm{C} / \mathrm{N}$ \\
\hline & & Grossa & Fina & Total & & & & & Total & $\mathrm{Ma}$ & Mi & \multicolumn{3}{|c|}{-----------\%------------ } \\
\hline & & \multicolumn{5}{|c|}{----------g kg-1---------- ------g kg-1----- } & \multicolumn{5}{|c|}{ 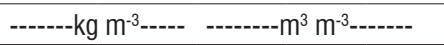 } & & & \\
\hline $0,60-1,02$ & $\mathrm{BA}$ & 137,61 & 63,24 & 200,85 & 290,66 & 508,50 & 632 & 2700 & 0,76 & 0,43 & 0,33 & 0,26 & 4,55 & 17,49 \\
\hline $1,02-1,52$ & Bw1 & 136,91 & 42,65 & 179,56 & 129,94 & 690,50 & 1051 & 2570 & 0,59 & 0,26 & 0,32 & 0,08 & 1,73 & 19,70 \\
\hline $1,52-2,00+$ & Bw2 & 148,16 & 37,41 & 185,57 & 108,44 & 706,00 & 1170 & 2710 & 0,56 & 0,21 & 0,35 & 0,04 & 0,69 & 16,20 \\
\hline \multicolumn{15}{|c|}{ P5 - LVda - Latossolo Vermelho Distrófico argissólico - Floresta aberta - Encosta } \\
\hline $0,00-0,20$ & A1 & 128,63 & 81,67 & 210,30 & 491,20 & 298,50 & 457 & 2684 & 0,82 & 0,46 & 0,36 & 0,74 & 8,41 & 11,33 \\
\hline $0,20-0,33$ & $\mathrm{~A} 2$ & 162,65 & 122,24 & 284,89 & 410,11 & 305,00 & 485 & 2624 & 0,81 & 0,42 & 0,39 & 0,48 & 7,43 & 15,33 \\
\hline $0,33-1,05$ & $\mathrm{BA}$ & 122,08 & 83,39 & 205,46 & 350,54 & 444,00 & 691 & 2720 & 0,74 & 0,32 & 0,41 & 0,27 & 5,31 & 19,50 \\
\hline $1,05-1,77$ & Bw1 & 170,00 & 41,42 & 211,42 & 126,58 & 662,00 & 880 & 2660 & 0,66 & 0,27 & 0,39 & 0,10 & 2,46 & 22,94 \\
\hline $1,77-2,20+$ & Bw2 & 179,24 & 47,41 & 226,66 & 120,34 & 653,00 & 1392 & 2667 & 0,48 & 0,08 & 0,40 & 0,04 & 0,82 & 19,40 \\
\hline \multicolumn{15}{|c|}{ P6 - LVd -Latossolo Vermelho Distrófico - Floresta aberta - Encosta } \\
\hline $0,00-0,18$ & A1 & 377,72 & 131,25 & 508,97 & 149,03 & 342,00 & 1280 & 2668 & 0,52 & 0,17 & 0,35 & 0,21 & 2,82 & 13,44 \\
\hline $0,18-0,28$ & $\mathrm{BA}$ & 316,48 & 131,27 & 447,75 & 163,75 & 388,50 & 1390 & 2613 & 0,47 & 0,15 & 0,32 & 0,10 & 1,60 & 14,94 \\
\hline $0,28-0,58$ & Bw1 & 306,97 & 113,75 & 420,72 & 146,28 & 433,00 & 1480 & 2667 & 0,53 & 0,20 & 0,34 & 0,08 & 1,04 & 12,88 \\
\hline $0,58-0,96$ & Bw2 & 292,04 & 133,03 & 425,07 & 99,93 & 475,00 & 1510 & 2686 & 0,46 & 0,14 & 0,32 & 0,05 & 0,60 & 11,31 \\
\hline $0,96-1,80+$ & Bw3 & 362,75 & 141,21 & 503,96 & 75,04 & 421,00 & 1590 & 2629 & 0,44 & 0,14 & 0,30 & 0,04 & 0,48 & 10,72 \\
\hline
\end{tabular}

$\mathrm{Ma}=$ macroporosidade $\mathrm{Mi}=$ microporosidade $\rho=$ densidade do solo; $\rho_{\mathrm{s}}=$ densidade das partículas

Tabela2 - Resultados das análises químicas dos perfis da topossequência, Serra de Parintins-AM.

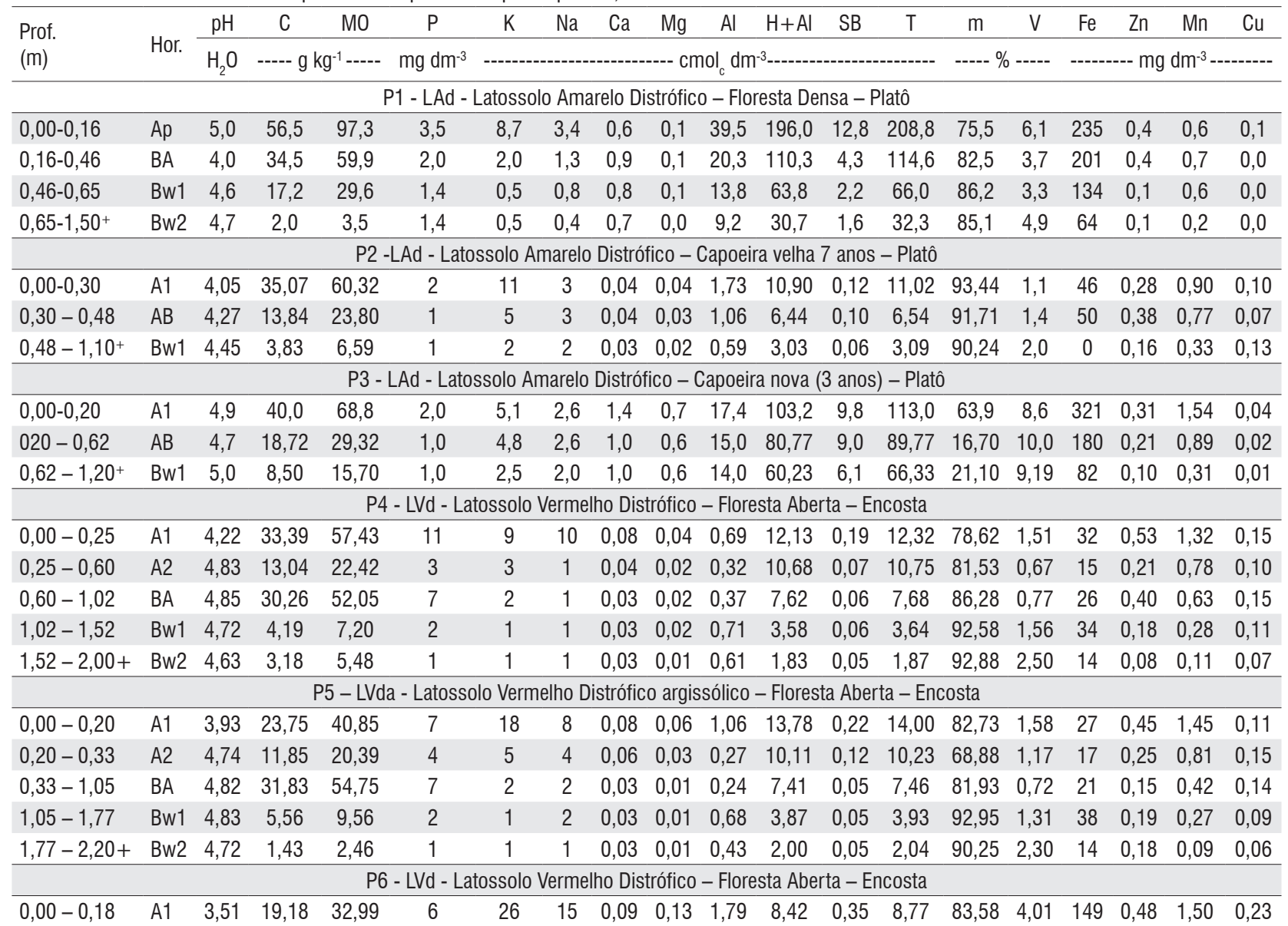


Tabela 2 - Continuação

\begin{tabular}{|c|c|c|c|c|c|c|c|c|c|c|c|c|c|c|c|c|c|c|c|}
\hline \multirow{2}{*}{$\begin{array}{l}\text { Prof. } \\
\text { (m) }\end{array}$} & \multirow{2}{*}{ Hor. } & $\mathrm{pH}$ & $C$ & MO & $P$ & $K$ & $\mathrm{Na}$ & $\mathrm{Ca}$ & $\mathrm{Mg}$ & $\mathrm{Al}$ & $\mathrm{H}+\mathrm{Al}$ & SB & $T$ & $\mathrm{~m}$ & V & $\mathrm{Fe}$ & $\mathrm{Zn}$ & $\mathrm{Mn}$ & $\mathrm{Cu}$ \\
\hline & & $\mathrm{H}_{2} \mathrm{O}$ & \multicolumn{2}{|c|}{---- $\mathrm{g} \mathrm{kg}^{-1}$---- } & $\mathrm{mg} \mathrm{dm}^{-3}$ & \multicolumn{8}{|c|}{ 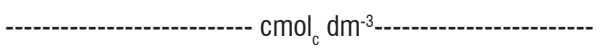 } & \multicolumn{2}{|c|}{---- \% ----- } & \multicolumn{4}{|c|}{-------- $\mathrm{mg} \mathrm{dm}^{3}$-------- } \\
\hline $0,18-0,28$ & BA & 3,89 & 7,00 & 12,04 & 2 & 7 & 3 & 0,05 & 0,03 & 1,06 & 4,73 & 0,11 & 4,84 & 90,56 & 2,29 & 189 & 0,38 & 1,04 & 0,21 \\
\hline $0,28-0,58$ & Bw1 & 4,06 & 4,59 & 7,89 & 1 & 4 & 1 & 0,04 & 0,02 & 0,92 & 4,15 & 0,07 & 4,23 & 92,50 & 1,76 & 151 & 0,18 & 1,05 & 0,16 \\
\hline $0,58-0,96$ & Bw2 & 4,23 & 2,78 & 4,78 & 2 & 4 & 3 & 0,05 & 0,02 & 0,76 & 3,55 & 0,09 & 3,65 & 89,12 & 2,56 & 89 & 1,23 & 0,94 & 0,26 \\
\hline $0,96-1,80+$ & Bw3 & 4,17 & 1,84 & 3,17 & 3 & 1 & 1 & 0,04 & 0,01 & 0,69 & 3,42 & 0,06 & 3,48 & 92,38 & 1,64 & 60 & 0,19 & 0,51 & 0,17 \\
\hline
\end{tabular}

$\mathrm{MO}=$ matéria orgânica; $\mathrm{T}=$ capacidade de troca de cátions $\left(\mathrm{S}+\mathrm{H}^{+}+\mathrm{Al} \mathrm{P}^{3+}\right) ; \mathrm{m}=$ saturação por alumínio $\left(\mathrm{Al}{ }^{3+} / \mathrm{S}+\mathrm{H}^{+}\right) .100 ; \mathrm{V}=$ saturação por bases $(100 . \mathrm{S} / \mathrm{T})$

Tabela 3 - Características morfológicas dos perfis estudados, topossequências, Serra de Parintins - AM

\begin{tabular}{|c|c|c|c|c|c|c|c|c|}
\hline Prof.(m) & Hor. & Textura & Cor úmida & $\begin{array}{l}\text { Estrutura } \\
\text { tipo, classe, grau }\end{array}$ & $\begin{array}{l}\text { Consistência } \\
\text { seca, úmida, molhada }\end{array}$ & Porosidade & Raízes & Transição \\
\hline \multicolumn{9}{|c|}{ P1 - LAd - Latossolo Amarelo Distrófico - Floresta Densa - Platô } \\
\hline $0,00-0,16$ & Ap & M.argilosa & 10YR 4/4 & $\begin{array}{l}\text { bl. sub., peq. e média, } \\
\text { moderada }\end{array}$ & lig. dura, friável, pl. e pegajoso & m. gr., p. peq. & $\begin{array}{l}\text { c.gr. e peq } \\
\text { finas. finas }\end{array}$ & Grad.e Horiz. \\
\hline $0,16-0,46$ & $\mathrm{BA}$ & M.argilosa & 10YR $7 / 6$ & $\begin{array}{l}\text { bl. sub., peq. e média, } \\
\text { fraca }\end{array}$ & macio, friável, pl. e peg. & m. gr., p. peq. & $\begin{array}{l}\text { C.gr. e c. peq } \\
\text { finas }\end{array}$ & Dif. e Hor. \\
\hline $0,46-0,65$ & Bw1 & M.argilosa & 10YR $7 / 7$ & $\begin{array}{l}\text { bl. sub., peq. e média, } \\
\text { fraca }\end{array}$ & macio, friável, pl. e peg. & $\begin{array}{l}\text { p. gr. e m. } \\
\text { peq. }\end{array}$ & $\begin{array}{l}\text { r. gr., c. peq. } \\
\text { finas }\end{array}$ & Dif. e Hor. \\
\hline $0,65-1,50$ & Bw2 & M.argilosa & 10YR 7/8 & $\begin{array}{l}\text { bl. sub., peq. e média, } \\
\text { fraca }\end{array}$ & $\begin{array}{l}\text { macio, friável, plástico e } \\
\text { pegajoso }\end{array}$ & r. gr. e m. peq. & $\begin{array}{l}\text { r.gr., ab. peq. } \\
\text { finas }\end{array}$ & Dif. e Hor. \\
\hline \multicolumn{9}{|c|}{ P2 - LAd - Latossolo Amarelo Distrófico - Capoeira 7 anos - Platô } \\
\hline $0,00-0,30$ & A & M.argilosa & 10YR 4/3 & $\begin{array}{l}\text { bl. sub., peq. e média, } \\
\text { moderada }\end{array}$ & $\begin{array}{l}\text { lig. dura, friável, não pl., lig. } \\
\text { peg. }\end{array}$ & c. peq. e gr. & $\begin{array}{l}\text { ab.peq finas., } \\
\text { p. gr }\end{array}$ & Grad.e Hor. \\
\hline $0,30-0,48$ & $A B$ & M.argilosa & 10YR 4/4 & $\begin{array}{l}\text { bl. sub., peq. e média, } \\
\text { moderada }\end{array}$ & lig. dura, friável, lig. pl., lig. peg. & m. peq., p. gr. & $\begin{array}{l}\text { p.peq finas., } \\
\text { p. gr. }\end{array}$ & Clara e Hor. \\
\hline $0,48-1,10$ & Bw1 & M.argilosa & 10YR 7/8 & $\begin{array}{l}\text { bl. sub., peq. e média, } \\
\text { fraca }\end{array}$ & lig. dura, m.friável, pl, peg. & m. peq., p. gr. & $\begin{array}{l}\text { r. peq finas., } \\
\text { r. gr. }\end{array}$ & Dif. e Hor. \\
\hline \multicolumn{9}{|c|}{ P3 -LAd - Latossolo Amarelo Distrófico - Capoeira nova (3 anos) - Platô } \\
\hline $0,00-0,20$ & A & M.argilosa & 10YR 4/4 & $\begin{array}{l}\text { bl. sub., peq. e média, } \\
\text { moderada }\end{array}$ & $\begin{array}{l}\text { lig. dura, friável, não pl., lig. } \\
\text { peg. }\end{array}$ & c. peq. e méd. & $\begin{array}{l}\text { ab.peq finas., } \\
\text { p. gr }\end{array}$ & $\begin{array}{l}\text { Grad. e } \\
\text { Horiz. }\end{array}$ \\
\hline $0,20-0,62$ & $A B$ & M.argilosa & 10YR 4/3 & $\begin{array}{l}\text { bl. sub., peq. e média, } \\
\text { moderada }\end{array}$ & lig. dura, friável, lig. pl., lig. peg. & m. peq., p. gr. & $\begin{array}{l}\text { p.peq finas., } \\
\text { p. gr. }\end{array}$ & Clara e Horiz. \\
\hline $0,62-1,20^{+}$ & Bw1 & M.argilosa & 10YR $7 / 7$ & $\begin{array}{l}\text { bl. sub., peq. e média, } \\
\text { fraca }\end{array}$ & lig. dura, m.friável, pl, peg. & m. peq., r. gr. & $\begin{array}{l}\text { r. peq finas., } \\
\text { r. gr. }\end{array}$ & Dif. e Hor. \\
\hline \multicolumn{9}{|c|}{ P4 - LVd - Latossolo Vermelho Distrófico - Floresta Aberta - Encosta } \\
\hline $0,00-0,25$ & A1 & Média & $\begin{array}{l}2,5 \mathrm{YR} \\
3 / 2\end{array}$ & bl. sub., m. peq., fraca & macio, friável, n-plástico, n-peg. & c.gr., p.peq. & $\begin{array}{l}\text { ab. peq. finas, } \\
\text { r.méd.; c.gr }\end{array}$ & Grad. e Hor. \\
\hline $0,25-0,60$ & A2 & Argilosa & $\begin{array}{l}2,5 \mathrm{YR} \\
3 / 2\end{array}$ & bl. sub., m. peq., fraca & macio, friável, n-plástico, n-peg. & m.gr., p.peq. & $\begin{array}{l}\text { ab. finas, r. } \\
\text { méd., p.gr. }\end{array}$ & Grad. e Hor. \\
\hline $0,60-1,02$ & $\mathrm{BA}$ & Argilosa & $\begin{array}{l}2,5 \mathrm{YR} \\
3 / 6\end{array}$ & bl. sub., peq., fraca & macio, friável, n-plástico, n-peg. & $\begin{array}{l}\text { c. méd. e gr.; } \\
\text { com. peq. }\end{array}$ & $\begin{array}{l}\text { r. peq.; p. méd.; } \\
\text { r. gr. }\end{array}$ & Grad. e Hor. \\
\hline $1,02-1,52$ & Bw1 & M.argilosa & $\begin{array}{l}2,5 \mathrm{YR} \\
5 / 8\end{array}$ & $\begin{array}{l}\text { bl. sub., peq., } \\
\text { moderada }\end{array}$ & $\begin{array}{l}\text { lig.duro, m.friável, plástico, } \\
\text { lig. peg. }\end{array}$ & $\begin{array}{l}\text { c. peq.; r. gr. e } \\
\text { méd. }\end{array}$ & $\begin{array}{l}\text { p. peq., p. } \\
\text { méd., r. gr. }\end{array}$ & Dif. e Hor. \\
\hline $\begin{array}{l}1,52- \\
2,00+\end{array}$ & Bw2 & M.argilosa & $\begin{array}{l}2,5 \mathrm{YR} \\
5 / 8\end{array}$ & $\begin{array}{l}\text { bl. sub., média, } \\
\text { moderada }\end{array}$ & lig.duro, m.friável, plástico, peg. & $\begin{array}{l}\text { c.peq.; r.gr e } \\
\text { méd. }\end{array}$ & $\begin{array}{l}\text { r. peq., méd. } \\
\text { e gr. }\end{array}$ & Dif. e Hor. \\
\hline \multicolumn{9}{|c|}{ P5 - LVda - Latossolo Vermelho Distrófico argissólico - Floresta Aberta - Encosta } \\
\hline $0,00-0,20$ & A1 & Média & $\begin{array}{l}2,5 \mathrm{YR} \\
2 / 2\end{array}$ & $\begin{array}{l}\text { bl. sub., pequena, } \\
\text { fraca }\end{array}$ & $\begin{array}{l}\text { macio, friável, lig.plástico, lig. } \\
\text { pegajoso }\end{array}$ & c.gr., p.peq. & $\begin{array}{l}\text { ab.peq finas e } \\
\text { méd., p. gr. }\end{array}$ & Dif. e Hor. \\
\hline $0,20-0,33$ & A2 & Média & $\begin{array}{l}2,5 \mathrm{YR} \\
3 / 2\end{array}$ & bl. sub., média, fraca & $\begin{array}{l}\text { lig.duro; friável; lig.plástico, lig. } \\
\text { pegajoso }\end{array}$ & m.gr., p.peq. & $\begin{array}{l}\text { c.méd.; p.peq., } \\
\text { r.gr. }\end{array}$ & Dif. e Hor. \\
\hline $0,33-1,05$ & $\mathrm{BA}$ & Argilosa & $\begin{array}{l}2,5 \mathrm{YR} \\
3 / 4\end{array}$ & bl. sub., média, fraca & $\begin{array}{l}\text { lig.duro; friável; lig.plástico, lig. } \\
\text { pegajoso }\end{array}$ & $\begin{array}{l}\text { c. méd. e gr.; } \\
\text { com. peq. }\end{array}$ & $\begin{array}{l}\text { p.peq., p.méd., } \\
\text { r.gr. }\end{array}$ & Grad. e Hor. \\
\hline
\end{tabular}


Tabela 3 - Continuação

\begin{tabular}{|c|c|c|c|c|c|c|c|c|}
\hline Prof.(m) & Hor. & Textura & Cor úmida & $\begin{array}{l}\text { Estrutura } \\
\text { tipo, classe, grau }\end{array}$ & $\begin{array}{l}\text { Consistência } \\
\text { seca, úmida, molhada }\end{array}$ & Porosidade & Raízes & Transição \\
\hline $1,05-1,77$ & Bw1 & M.argilosa & $\begin{array}{l}2,5 \mathrm{YR} \\
4 / 8\end{array}$ & $\begin{array}{l}\text { bl. sub., média, } \\
\text { moderada }\end{array}$ & duro; firme; plástico; pegajoso & $\begin{array}{l}\text { c. peq.; r. gr. e } \\
\text { méd. }\end{array}$ & $\begin{array}{l}\text { p.peq., p.gr., } \\
\text { r.méd. }\end{array}$ & Clara e Hor. \\
\hline $\begin{array}{l}1,77- \\
2,20+\end{array}$ & Bw2 & M.argilosa & $\begin{array}{l}2,5 \mathrm{YR} \\
5 / 8\end{array}$ & bl. sub., média, forte & $\begin{array}{l}\text { duro, firme, m. plástico, } \\
\text { m.pegajoso }\end{array}$ & $\begin{array}{l}\text { c.peq.; r.gr e } \\
\text { méd. }\end{array}$ & $\begin{array}{l}\text { p.peq., r.méd. } \\
\text { e gr. }\end{array}$ & Dif. e Hor. \\
\hline \multicolumn{9}{|c|}{ P6 - LVd - Latossolo Vermelho Distrófico - Floresta Aberta - Encosta } \\
\hline $0,00-0,18$ & A & Média & $\begin{array}{l}2,5 \mathrm{YR} \\
4 / 6\end{array}$ & $\begin{array}{l}\text { bl. sub. peq e m. peq., } \\
\text { moderada }\end{array}$ & $\begin{array}{l}\text { lig.duro, friável, lig.plástico, lig. } \\
\text { pegajoso }\end{array}$ & c.gr., p.peq. & $\begin{array}{l}\text { ab.peq finas e } \\
\text { méd., p. gr. }\end{array}$ & Grad. e Hor \\
\hline $0,18-0,28$ & $\mathrm{BA}$ & Média & $\begin{array}{l}2,5 \mathrm{YR} \\
4 / 6\end{array}$ & $\begin{array}{l}\text { bl. sub. peq e média, } \\
\text { moderada }\end{array}$ & $\begin{array}{l}\text { lig.duro, friável, plástico, lig. } \\
\text { pegajoso }\end{array}$ & m.gr., p.peq. & $\begin{array}{l}\text { c.méd.; p.peq., } \\
\text { r.gr. }\end{array}$ & Grad. e Hor \\
\hline $0,28-0,58$ & Bw1 & Argilosa & $\begin{array}{l}2,5 \mathrm{YR} \\
5 / 8\end{array}$ & $\begin{array}{l}\text { bl. sub. peq. e média, } \\
\text { forte }\end{array}$ & $\begin{array}{l}\text { duro, friável, plástico, lig. } \\
\text { pegajoso }\end{array}$ & $\begin{array}{l}\text { c. méd. e gr.; } \\
\text { com. peq. }\end{array}$ & $\begin{array}{l}\text { p.peq., p.méd., } \\
\text { r.gr. }\end{array}$ & Dif. e Hor. \\
\hline $0,58-0,96$ & Bw2 & Argilosa & $\begin{array}{l}2,5 \mathrm{YR} \\
5 / 8\end{array}$ & bl. sub. média, forte & $\begin{array}{l}\text { duro, m. friável, plástico, lig. } \\
\text { pegajoso }\end{array}$ & $\begin{array}{l}\text { c. peq.; r. gr. e } \\
\text { méd. }\end{array}$ & $\begin{array}{l}\text { p.peq., p.gr., } \\
\text { r.méd. }\end{array}$ & Dif. e Hor. \\
\hline $\begin{array}{l}0,96- \\
1,80+\end{array}$ & Bw3 & Argilosa & $\begin{array}{l}2,5 \mathrm{YR} \\
6 / 8\end{array}$ & bl. sub. média, forte & $\begin{array}{l}\text { duro, m. friável, plástico, lig. } \\
\text { pegajoso }\end{array}$ & $\begin{array}{l}\text { c.peq.; r.gr e } \\
\text { méd. }\end{array}$ & $\begin{array}{l}\text { p.peq., r.méd. } \\
\text { e gr. }\end{array}$ & Dif. e Hor. \\
\hline
\end{tabular}

bl. sub. = bloco subangular; peq. = pequena; lig. = ligeiramente; $\mathrm{m} .=$ muito; pl. = plástico; peg. = pegojoso; m. gr. = muito grande; p.peq. = pouco pequenos; c. peq. = comuns pequenos; r. gr. = raros grandes; c. méd. = comuns médios; c. gr. = comuns grandes; ab. peq. $=$ abundantes pequenos; Grad. $=$ gradual; Hor. $=$ horizontal; Dif. $=$ difusa

Tabela 4 - Parâmetros estatísticos dos dados de condutividade hidráulica ( $\mathrm{cm} \mathrm{dia}^{-1}$ ), valores originais, em diferentes coberturas vegetais de uma topossequência de solos localizada na Serra de Parintins, Manaus, obtida em laboratório pelo método do permeâmetro de carga constante e decrescente utilizando amostras indeformadas.

\begin{tabular}{|c|c|c|c|c|c|c|c|c|c|c|c|c|c|}
\hline \multicolumn{8}{|c|}{ Permeâmetro de carga constante } & \multicolumn{6}{|c|}{ Permeâmetro de carga decrescente } \\
\hline Prof. (m) & Hor & Mín. & Máx. & MD & Média & $\mathrm{s}$ & CV(\%) & Mín. & Máx. & MD & Média & s & $\mathrm{CV}(\%)$ \\
\hline \multicolumn{14}{|c|}{ P1 - LAd - Latossolo Amarelo Distrófico - Floresta Densa - Platô } \\
\hline $0,00-0,16$ & Ap & 1101,30 & 4129,01 & 2065,23 & 2466,09 & 1073,90 & 43,54 & 1151,30 & 1726,98 & 863,49 & 937,68 & 489,89 & 52,24 \\
\hline $0,16-0,46$ & BA & 862,41 & 1035,12 & 862,40 & 805,77 & 195,64 & 24,28 & 115,13 & 690,79 & 690,79 & 1013,16 & 859,72 & 84,85 \\
\hline $0,46-0,65$ & Bw1 & 299,08 & 396,09 & 396,09 & 533,88 & 326,93 & 61,23 & 95,50 & 345,39 & 172,69 & 368,33 & 402,82 & 109,36 \\
\hline $0,65-1,50$ & Bw2 & 705,71 & 832,19 & 678,20 & 645,33 & 127,58 & 19,77 & 57,88 & 62,79 & 62,79 & 75,94 & 22,27 & 29,32 \\
\hline \multicolumn{14}{|c|}{ P2 - LAd - Latossolo Amarelo Distrófico - Capoeira velha (7 anos) - Platô } \\
\hline $0,00-0,30$ & A1 & 2180,90 & 2793,93 & 2257,53 & 2571,08 & 914,90 & 35,58 & 345,40 & 1883,98 & 714,61 & 1026,29 & 649,22 & 63,25 \\
\hline $0,30-0,48$ & $A B$ & 877,93 & 1336,92 & 877,92 & 925,33 & 285,10 & 30,81 & 115,13 & 172,69 & 230,26 & 414,47 & 303,30 & 73,17 \\
\hline $0,48-1,10$ & Bw1 & 272,39 & 519,62 & 519,62 & 891,16 & 572,22 & 64,21 & 98,68 & 115,13 & 115,13 & 162,28 & 110,99 & 68,39 \\
\hline \multicolumn{14}{|c|}{ P3 - LAd - Latossolo Amarelo Distrófico - Capoeira nova (3 anos) - Platô } \\
\hline $0,00-0,20$ & $\mathrm{~A} 1$ & 2610,00 & 5120,16 & 4761,51 & 4405,23 & 1014,90 & 23,03 & 345,40 & 1726,98 & 986,84 & 1049,34 & 594,06 & 6,61 \\
\hline $0,20-0,62$ & $A B$ & 1890,00 & 4038,88 & 4038,88 & 3709,41 & 1309,80 & 35,31 & 230,26 & 460,52 & 345,39 & 322,36 & 86,15 & 26,73 \\
\hline $0,62-1,20^{+}$ & Bw1 & 829,91 & 869,26 & 838,49 & 758,04 & 186,44 & 24,59 & 76,19 & 172,69 & 98,68 & 112,27 & 32,65 & 29,08 \\
\hline \multicolumn{14}{|c|}{ P4 - LVd - Latossolo Vermelho Distrófico - Floresta Aberta - Encosta } \\
\hline $0,00-0,25$ & A1 & 3815,60 & 4913,94 & 3815,63 & 3199,34 & 1385,90 & 43,31 & 345,40 & 2302,64 & 1151,32 & 1128,29 & 707,47 & 62,70 \\
\hline $0,25-0,60$ & $\mathrm{~A} 2$ & 1074,50 & 3109,27 & 2145,54 & 1972,74 & 719,80 & 36,48 & 222,84 & 901,03 & 313,99 & 477,54 & 269,88 & 56,51 \\
\hline $0,60-1,02$ & $\mathrm{BA}$ & 2708,10 & 2718,04 & 2718,04 & 3148,37 & 601,75 & 19,11 & 40,39 & 98,68 & 84,58 & 75,43 & 30,98 & 41,07 \\
\hline $1,02-1,52$ & Bw1 & 645,86 & 724,42 & 574,74 & 581,37 & 108,71 & 18,69 & 38,37 & 57,56 & 57,56 & 69,01 & 26,05 & 37,75 \\
\hline $1,52-2,00+$ & Bw2 & 651,66 & 757,06 & 651,66 & 633,83 & 96,34 & 15,20 & 38,37 & 57,56 & 57,56 & 66,20 & 27,87 & 42,10 \\
\hline \multicolumn{14}{|c|}{ P5 - Latossolo Vermelho Distrófico argissólico - Floresta Aberta - Encosta } \\
\hline $0,00-0,20$ & A1 & 5957,60 & 8210,45 & 5957,56 & 6242,93 & 1277,30 & 20,46 & 276,32 & 2302,64 & 986,84 & 1529,55 & 1181,44 & 77,24 \\
\hline $0,20-0,33$ & A2 & 6452,00 & 10822,90 & 6451,99 & 7707,59 & 3539,60 & 45,92 & 272,68 & 2072,38 & 272,68 & 714,72 & 708,58 & 99,13 \\
\hline $0,33-1,05$ & BA & 2429,90 & 2759,62 & 2759,62 & 2593,51 & 726,26 & 28,00 & 213,65 & 2302,64 & 1726,98 & 1326,37 & 984,21 & 74,20 \\
\hline
\end{tabular}


Tabela 4 - Continuação

\begin{tabular}{cccccccccccccc}
\hline $1,05-1,77$ & Bw1 & 472,60 & 615,53 & 503,12 & 510,62 & 75,51 & 14,78 & 35,18 & 52,59 & 56,93 & 74,86 & 35,67 & 47,65 \\
$1,77-2,20+$ & Bw2 & 93,63 & 783,32 & 121,06 & 601,11 & 729,82 & 121,41 & 61,31 & 98,68 & 98,68 & 1459,75 & 2724,26 & 186,62 \\
\hline \multicolumn{8}{c}{} & \multicolumn{7}{c}{ P6 - LVd - Latossolo Vermelho Distrófico - Mata Ciliar - Encosta } \\
\hline $0,00-0,18$ & A1 & 1919,50 & 11510,10 & 1919,53 & 5674,80 & 5173,60 & 91,16 & 227,54 & 1649,65 & 1649,65 & 1860,12 & 1258,88 & 67,67 \\
$0,18-0,28$ & BA & 625,54 & 816,98 & 816,98 & 1165,36 & 961,14 & 82,47 & 281,81 & 3301,20 & 296,26 & 959,92 & 1182,93 & 123,23 \\
$0,28-0,58$ & Bw1 & 1453,70 & 2650,75 & 2650,75 & 2409,92 & 1249,40 & 51,84 & 232,85 & 1726,98 & 1726,98 & 1619,86 & 1308,91 & 80,80 \\
$0,58-0,96$ & Bw2 & 167,34 & 393,53 & 355,80 & 309,92 & 87,81 & 28,33 & 33,60 & 48,25 & 80,79 & 87,32 & 50,61 & 57,95 \\
$0,96-1,80+$ & Bw3 & 228,49 & 636,45 & 948,11 & 2509,90 & 3532,20 & 140,73 & 61,31 & 115,31 & 156,99 & 237,74 & 229,47 & 96,52 \\
\hline
\end{tabular}

MD = mediana; $S$ = desvio padrão; CV = coeficiente de variação. Os valores foram obtidos a partir de, no mínimo, 4 leituras em cada amostra, sendo cada horizonte, constituído por 5 repetições.

Tabela 5 - Parâmetros estatísticos dos dados transformados de condutividade hidráulica (cm dia ${ }^{-1}$ ) utilizando o método do permeâmetro de carga constante e decrescente em amostras de uma topossequência no Município de Parintins-AM.

\begin{tabular}{|c|c|c|c|c|c|c|c|c|c|c|c|c|c|}
\hline \multicolumn{8}{|c|}{ Permeâmetro de carga constante } & \multicolumn{6}{|c|}{ Permeâmetro de carga decrescente } \\
\hline Prof. (m) & Hor. & Mín. & Máx. & MD & Média & s & $\mathrm{CV}(\%)$ & Mín. & Máx. & MD & Média & s & $\mathrm{CV}(\%)$ \\
\hline \multicolumn{14}{|c|}{ P1 - LAd - Latossolo Amarelo Distrófico - Floresta Densa - Platô } \\
\hline $0,00-0,16$ & Ap & 3,04 & 3,61 & 3,31 & $3,34 a$ & 0,19 & 5,96 & 3,06 & 3,23 & 2,93 & $2,89 \mathrm{~b}$ & 0,27 & 9,60 \\
\hline $0,16-0,46$ & BA & 2,93 & 3,01 & 2,93 & $2,89 a$ & 0,11 & 3,96 & 2,06 & 2,83 & 2,83 & $2,77 a$ & 0,49 & 17,98 \\
\hline $0,46-0,65$ & Bw1 & 2,47 & 2,59 & 2,59 & $2,65 a$ & 0,24 & 9,32 & 1,98 & 2,53 & 2,23 & $2,34 a$ & 0,42 & 18,19 \\
\hline $0,65-1,50$ & Bw2 & 2,84 & 2,92 & 2,83 & $2,80 a$ & 0,08 & 3,14 & 1,76 & 1,79 & 1,79 & $1,86 \mathrm{~b}$ & 0,11 & 6,32 \\
\hline \multicolumn{14}{|c|}{ P2 - LAd - Latossolo Amarelo Distrófico - Capoeira velha (7 anos) - Platô } \\
\hline $0,00-0,30$ & A1 & 3,33 & 3,44 & 3,35 & $3,38 \mathrm{a}$ & 0,15 & 4,47 & 2,53 & 3,27 & 2,85 & $2,91 b$ & 0,29 & 10,21 \\
\hline $0,30-0,48$ & $A B$ & 2,94 & 3,12 & 2,94 & $2,94 a$ & 0,14 & 5,08 & 2,06 & 2,23 & 2,36 & $2,48 b$ & 0,34 & 13,75 \\
\hline $0,48-1,10$ & Bw1 & 2,43 & 2,71 & 2,71 & $2,85 a$ & 0,29 & 10,52 & 1,99 & 2,06 & 2,06 & $2,13 b$ & 0,22 & 10,49 \\
\hline \multicolumn{14}{|c|}{ P3 - LAd - Latossolo Amarelo Distrófico - Capoeira nova (3 anos) - Platô } \\
\hline $0,00-0,20$ & A1 & 3,41 & 3,70 & 3,67 & $3,63 a$ & 0,11 & 3,17 & 2,53 & 3,23 & 2,99 & $2,93 b$ & 0,28 & 9,85 \\
\hline $0,20-0,62$ & $A B$ & 3,27 & 3,60 & 3,60 & $3,53 a$ & 0,16 & 4,76 & 2,36 & 2,66 & 2,53 & $2,49 \mathrm{~b}$ & 0,11 & 4,65 \\
\hline $0,62-1,20^{+}$ & Bw1 & 2,91 & 2,93 & 2,92 & $2,86 \mathrm{a}$ & 0,13 & 4,79 & 1,88 & 2,23 & 1,99 & $2,03 \mathrm{~b}$ & 0,11 & 5,74 \\
\hline \multicolumn{14}{|c|}{ P4 - LVd Latossolo Vermelho Distrófico - Floresta Aberta - Encosta } \\
\hline $0,00-0,25$ & A1 & 3,58 & 3,69 & 3,58 & $3,45 a$ & 0,21 & 6,31 & 2,53 & 3,36 & 3,06 & $2,95 b$ & 0,30 & 10,38 \\
\hline $0,25-0,60$ & $\mathrm{~A} 2$ & 3,03 & 3,49 & 3,33 & $3,26 a$ & 0,16 & 5,06 & 2,34 & 2,95 & 2,49 & $2,61 b$ & 0,24 & 9,25 \\
\hline $0,60-1,02$ & $\mathrm{BA}$ & 3,43 & 3,43 & 3,43 & $3,49 a$ & 0,07 & 2,23 & 1,60 & 1,99 & 1,92 & $1,83 b$ & 0,20 & 10,90 \\
\hline $1,02-1,52$ & Bw1 & 2,81 & 2,86 & 2,75 & $2,75 a$ & 0,08 & 3,18 & 1,58 & 1,76 & 1,76 & $1,80 \mathrm{~b}$ & 0,15 & 8,73 \\
\hline $1,52-2,00+$ & Bw2 & 2,81 & 2,87 & 2,81 & $2,79 a$ & 0,06 & 2,40 & 1,58 & 1,76 & 1,76 & $1,78 \mathrm{~b}$ & 0,17 & 9,69 \\
\hline \multicolumn{14}{|c|}{ P5 - LVda - Latossolo Vermelho Distrófico argissolico - Floresta Aberta - Encosta } \\
\hline $0,00-0,20$ & A1 & 3,77 & 3,91 & 3,77 & $3,78 \mathrm{a}$ & 0,08 & 2,36 & 2,44 & 3,36 & 2,99 & $3,02 b$ & 0,39 & 12,96 \\
\hline $0,20-0,33$ & A2 & 3,80 & 4,03 & 3,80 & $3,83 a$ & 0,22 & 5,97 & 2,43 & 3,31 & 2,43 & $2,67 b$ & 0,37 & 14,08 \\
\hline $0,33-1,05$ & $\mathrm{BA}$ & 3,38 & 3,44 & 3,44 & $3,39 a$ & 0,14 & 4,13 & 2,32 & 3,36 & 3,23 & $2,84 a$ & 0,59 & 20,99 \\
\hline $1,05-1,77$ & Bw1 & 2,67 & 2,78 & 2,70 & $2,70 a$ & 0,06 & 2,43 & 1,54 & 1,72 & 1,75 & $1,82 b$ & 0,20 & 11,19 \\
\hline $1,77-2,20+$ & Bw2 & 1,97 & 2,89 & 2,08 & $2,38 a$ & 0,60 & 25,17 & 1,78 & 1,99 & 1,99 & $2,33 a$ & 0,76 & 32,56 \\
\hline \multicolumn{14}{|c|}{ P6 - LVd - Latossolo Vermelho Distrófico - Floresta Aberta - Encosta } \\
\hline $0,00-0,18$ & A1 & 3,28 & 4,06 & 3,28 & $3,52 \mathrm{a}$ & 0,45 & 13,00 & 2,35 & 3,21 & 3,21 & $3,10 \mathrm{a}$ & 0,43 & 14,03 \\
\hline $0,18-0,28$ & $\mathrm{BA}$ & 2,79 & 2,91 & 2,91 & $2,90 \mathrm{a}$ & 0,39 & 13,70 & 2,45 & 3,51 & 2,47 & $2,72 \mathrm{a}$ & 0,43 & 15,82 \\
\hline $0,28-0,58$ & Bw1 & 3,16 & 3,42 & 3,42 & $3,29 a$ & 0,30 & 9,26 & 2,36 & 3,23 & 3,23 & $2,90 a$ & 0,61 & 21,31 \\
\hline $0,58-0,96$ & Bw2 & 2,22 & 2,59 & 2,55 & $2,47 a$ & 0,14 & 5,76 & 1,52 & 1,68 & 1,90 & $1,86 b$ & 0,24 & 13,35 \\
\hline $0,96-1,80+$ & Bw3 & 2,35 & 2,80 & 2,97 & $3,03 a$ & 0,53 & 17,46 & 1,78 & 2,06 & 2,19 & $2,22 b$ & 0,34 & 15,55 \\
\hline
\end{tabular}

MD = mediana; $S$ = desvio padrão; $C V=$ coeficiente de variação. Os valores foram obtidos a partir de, no mínimo, 4 leituras em cada amostra, sendo cada horizonte, constituído por 5 repetições. Letras iguais representam similaridade quanto Ko e diferentes desigualdade quanto Ko considerando os dois métodos utilizados. Utilizou-se Tukey $5 \%$ de probabilidade. 
A

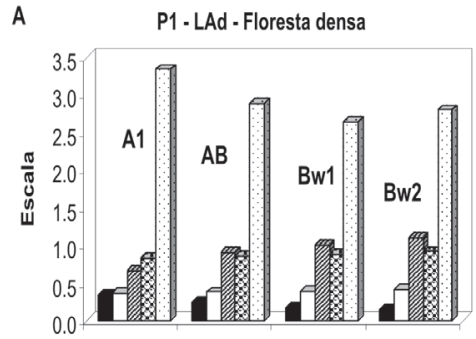

Macro $\square$ Micro Densidade $\mathbf{0}$ Argila $\square K_{0}$

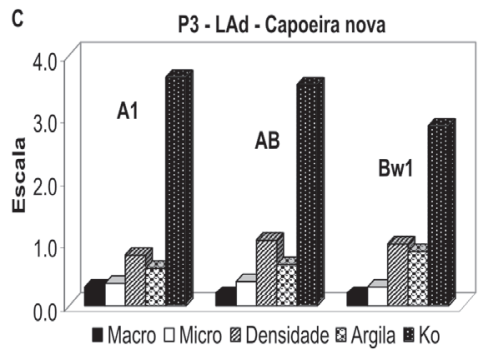

E

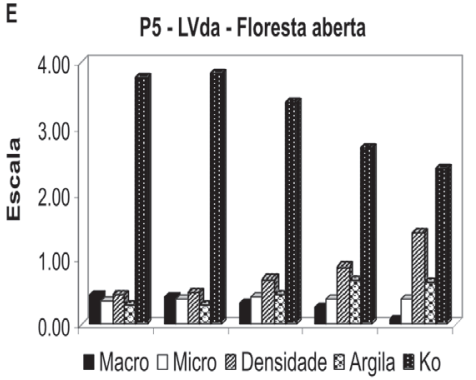

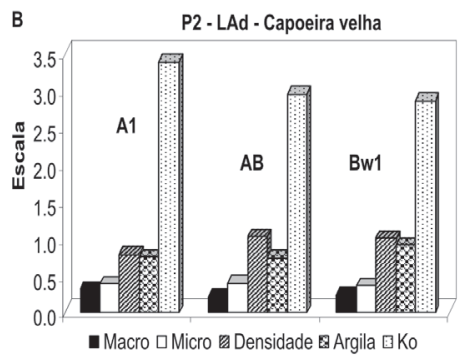

D

P4 - LVd - Floresta aberta

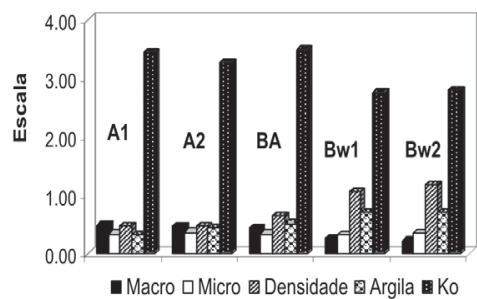

F

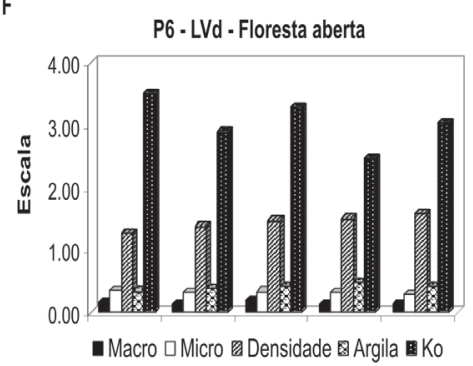

Figura 8 - Gráfico representativo da macroporosidade $\left(\mathrm{m}^{3} \mathrm{~m}^{-3}\right)$, microporosidade $\left(\mathrm{m}^{3} \mathrm{~m}^{-3}\right)$, densidade $\left(\mathrm{Mg} \mathrm{m}^{-3}\right)$, teor de argila $\left(\mathrm{g} \mathrm{g}^{-1}\right)$ e condutividade hidráulica saturada - Ko $\left(\mathrm{cm} \mathrm{dia}^{-1}\right)$

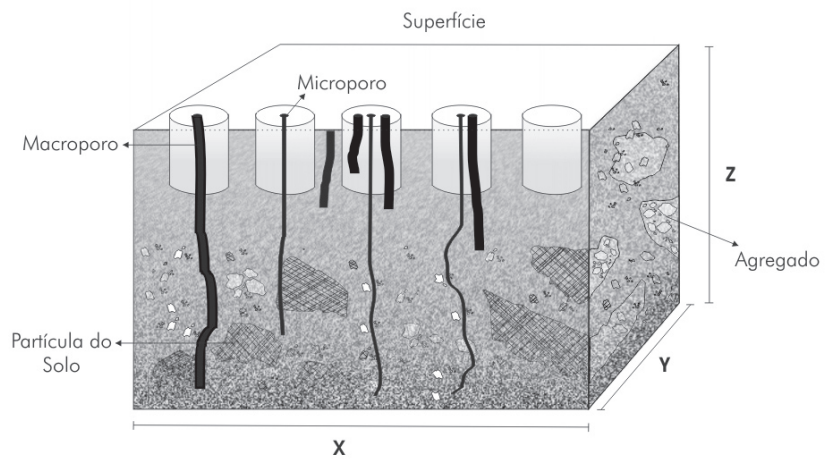

Figura 7 - Desenho esquemático representativo de diferentes disposições dos macroporos nos solos pequenas variações no teor de argila. Outro fator que pode explicar o maior valor de Ko na capoeira nova é a forma de utilização da área (pousio e rotação de cultura), promovendo a agregação do solo. Talvez Ko seja mais sensível a mudanças nas propriedades físicas do solo do que as alteraçóes nas coberturas vegetais sobre o solo.

\section{CONCLUSÕES}

O método do PCC é o mais apropriado para a classe dos Latossolos estudados, apresentando os menores coeficientes de variação e desvio padrão ao longo da topossequência;

Os valores de Ko para a topossequência de solos amazônicos estudada estiveram distribuídos entre P1(2,65 à $\left.3,34 \mathrm{~cm} \mathrm{dia}^{-1}\right), \mathrm{P} 2\left(2,85\right.$ à $\left.3,38 \mathrm{~cm} \mathrm{dia}^{-1}\right), \mathrm{P} 3(2,86$ à $3,63 \mathrm{~cm}$ $\left.\mathrm{dia}^{-1}\right), \mathrm{P} 4\left(2,75\right.$ à $\left.3,49 \mathrm{~cm} \mathrm{dia}^{-1}\right), \mathrm{P} 5\left(2,38\right.$ à $\left.3,83 \mathrm{~cm} \mathrm{dia}^{-1}\right)$ e P6 
$\left(2,47\right.$ à $\left.3,52 \mathrm{~cm} \mathrm{dia}^{-1}\right)$; havendo uma tendência para maiores valores de $K_{o}$ na superfície;

A escolha de Ko como parâmetro hídrico de análise em solos porosos na superfície e muito argilosos necessita ser realizada com precaução, evitando a interrupção do poros e compactação da amostra.

Devido o desenvolvimento de maior incidência de macroporos na superfície em áreas de floresta, bem como a presença de raízes grandes e finas, recomenda-se a utilização de métodos de campo para determinação de Ko.

Mudanças na condutividade hidráulica saturada estiveram mais relacionadas a alteraçôes nas propriedades físicas do solo e posição no relevo do que nas alterações das coberturas vegetais ao longo da topossequência.

\section{AGRADECIMENTOS}

À FAPEAM, pelo financiamento do projeto 811/04. Ao Laboratório de Análise de Solo da EMBRAPA e ao Laboratório Temático de Solo e Planta do INPA, pela oportunidade de realização das análises físicas, químicas e hídricas. Ao INPA pelo apoio na continuidade do projeto, na pessoa do Dr. Flávio Luizão.

\section{LITERATURA CITADA}

ANDERSON, S.N. \& CASSEL, D. 1986. Statistical and autoregressive analysis of soil physical properties of Portsmouth Sandy Loam. Soil Science Society of Amarican Journal, 50: 1096-1104

ARGENTON, J.; ALBUQUERQUE, J.A.; BAYER, C.; WILDNER, L.P. 2005. Comportamento de atributos relacionados com a forma da estrutura de Latossolo Vermelho sob sistemas de preparo e plantas de cobertura. Revista Brasileira de Ciência do Solo, 29: 425-435

BAGARELLO, V.; PROVENZANO, G. 1996. Factors affecting field and laboratory measurement of saturated hydraulic conductivity. American Society of Agricultural Engineers, 39(1):153-159.

BOUMA, J.; JONGMANS, A.; STEIN, A. 1989. Characterizing spatially variable hydraulic properties of a boulder clay deposit in the Netherlands. Geoderma, 45: 19-29.

EMBRAPA.1984. Centro Nacional de Pesquisa Agroflorestal. Boletim Agrometeorológico. Manaus, EMBRAPA - UEPAE (Documento, 6).

EMBRAPA. 1997. Manual de Métodos de Análise de Solo. $2^{a}$ edição. rev. atual. Centro Nacional de Pesquisa de Solos. Rio de Janeiro, 212p. (EMBRAPA-CNPS. Documentos; 1).

EMBRAPA.1999a. Sistema Brasileiro de Classificação de Solos. Centro Nacional de Pesquisa de Solos. Rio de Janeiro, EMBRAPA-CNPS, 412 p.

EMBRAPA.1999b. Manual de Analises Químicas de Solos, Plantas e Fertilizantes. Embrapa Solos. Brasília: Embrapa comunicação para transferência de tecnologia, $370 \mathrm{p}$.
GARDNER, W.H. 1986. Water content. In: KLUTE, A. ed. Methods of soil analysis. Part I. Agronomy Monograph Séries $\mathrm{n}^{\circ}$ 9, Madison, Winconsin, Cap. 21, p. 493-544.

GONÇALVES, J.L.M.; MELLO, S.L.M. 2000. O sistema radicular das arvores. In: GONÇAVES, J.L.M.; BENEDETTI, V. (ed). Nutrição e fertilização florestal. Piracicaba: IPEF/FAPESP, p. 219-267.

HILLEL, D. 1971. Soil and water. Physical principles and processes. New York, Academic Press, 288p.

HILLEL, D. 1982. Introduction to Soil Physics. New York, Academic Press, 365p.

LEMOS, R.C.; SANTOS, R.D. dos. 1996. Manual de descrição e coleta de solo no campo. $3^{\text {a }}$ ed. Campinas, SP:SBCS/CNPS, $83 \mathrm{p}$.

LIBARDI, P.L. Dinâmica da água no solo. $2^{a}$ edição. Piracicaba, 2000: o autor. 509p.

LOGSDON, S.D.; JAYNES, D.B. 1996. Spatial variability of hydraulic conductivity in a cultivated field at different times. Soil Science Society of America Journal, 60: 703-709.

MARQUES, J.D.; LIBARDI, P.L. ; TEIXEIRA, W.G.; REIS, A.M. 2004. Estudo de parâmetros físicos, químicos e hídricos de um Latossolo Amarelo, na regiāo Amazônica. Acta Amazônica, 34(2):145-154.

MOHANTY, B.P.; KANWAR, R.S.; EVERTS, C.J. 1994. Comparison of saturated hydraulic conductivity measurement methods for a glacial-till soil. Soil Science Society of América Journal, 58(3):672-677.

TEIXEIRA, C. F. A.; MORAES, S. O.; SIMONETE, M. A. 2005. Desempenho do Tensiômetro, TDR e Sonda de Nêutrons na determinação da Umidade e Condutividade Hidráulica do Solo. Revista brasileira de Ciência do Solo, v. 29, n. 2, p. 161-168.

TEIXEIRA, W.G. 2001. Land use effects on Soil Physical and Hydraulic Properties of a Clayey Ferralsol in the Central Amazon. University of Bayreuth. Bayreuth - Alemanhã Tese de Doutorado. 255p.

VAN ES, H.M.; OGDEN, C.B.; HILL, R.L.; SCHINDELBECK, R.R.; TSEGAYE, T. 1999. Integrated assessment of space, time, and management-related variability of soil hydraulic properties. Soil Science Society of American Journal, 63: 1599-1608.

VIEIRA, S.R.; NIELSEN, D.R.; BIGGAR, J.W. 1981. Spatial variability of field-measured infiltration rate. Soil Science Society of America Journal, 45: 1040-1048.

YOUNGS, E.G.1991. Hydraulic conductivity of saturated soils. In: SMITH, K.A.; MULLINS, C.E. (Ed). Soil analysis: physical methods. New York: Marcel Dekker. cap. 4, p. 161-207.

WARRICK, A.W.; NIELSEN, D.R. 1980. Spatial variability of soil physical properties in the field. In: HILLEL, D. (ed). Applications of soil physics. New York: Academic Press, cap. 13, p. 319-344.

Wilkinson, L. 1998. Systat: The system for statistics. Evanston, IL, Systat Inc.

Recebido em 09/01/2006

Aceito em 02/05/2008 
